\title{
The lipid droplet protein Pgc1 controls the subcellular distribution of phosphatidylglycerol
}

Dominika Kubalová ${ }^{1}$, Petra Veselá ${ }^{2}$, Thuraya Awadová ${ }^{2}$ Günther Daum ${ }^{3}$ Jan Malínský², Mária Balážová ${ }^{*}$

${ }^{1}$ Department of Membrane Biochemistry, Institute of Animal Biochemistry and Genetics, Centre of Biosciences, Slovak Academy of Sciences, 84005 Bratislava, Slovakia

${ }^{2}$ Microscopy Unit, Institute of Experimental Medicine, Academy of Sciences of the Czech Republic, 14220 Prague, Czech Republic

${ }^{3}$ Institute of Biochemistry, Graz University of Technology, 8010 Graz, Austria

Corresponding author: Mária Balážová, Institute of Animal Biochemistry and Genetics, Centre of Biosciences, Slovak Academy of Sciences, Dubravska cesta 9, 84005 Bratislava, Slovakia

Maria.Balazova@savba.sk

Running title: Homeostasis of phosphatidylglycerol

Keywords: phosphatidylglycerol, Pgc1, lipid degradation, lipid droplets, yeast 


\begin{abstract}
The biosynthesis of yeast phosphatidylglycerol (PG) takes place in the inner mitochondrial membrane. Outside mitochondria, the abundance of PG is low. Here we present evidence that the subcellular distribution of PG is maintained by locally controlled enzymatic activity of the PGspecific phospholipase, Pgc1. We document that the Pgc1 absence leads to spreading of PG over various cellular membranes. Fluorescently labeled Pgc1 protein strongly accumulates at the surface of lipid droplets (LD). We show, however, that LD are not only dispensable for Pgc1mediated PG degradation, but even host no phospholipase activity of Pgc1. Our in vitro assays document the capability of LD-accumulated Pgc1 to degrade PG upon entry to membranes of the endoplasmic reticulum, mitochondria, and even of artificial phospholipid vesicles. FRAP analysis confirms continuous exchange of GFP-Pgc1 within individual LD in situ, suggesting that a steady-state equilibrium exists between $\mathrm{LD}$ and membranes to regulate immediate phospholipase activity of Pgc1. In this model, LD serve as storage place and shelter Pgc1 preventing untimely degradation, while both phospholipase activity and degradation of the enzyme occur in membranes.
\end{abstract}




\section{Introduction}

Phosphatidylglycerol (PG) is an anionic phospholipid which exhibits a great variety of biological functions. It is one of the major structural lipids in bacterial membranes ((Sohlenkamp \& Geiger, 2016), and citations therein). In eukaryotic cells, PG represents a minor fraction of total glycerophospholipds, but it plays indispensable roles in optimizing their energy metabolism. Moreover, PG is an essential metabolic precursor of cardiolipin, the main lipid of the inner mitochondrial membrane (Horvath \& Daum, 2013; Zinser \& Daum, 1995). Cells deficient in PG biosynthesis exhibit severe phenotypic defects related to impaired mitochondrial function (Chang et al, 1998a; Janitor et al, 1995; Zhong \& Greenberg, 2005; Zhong et al, 2005, 2007). PG is also an important structural and functional lipid of photosynthetic membranes (Kobayashi, 2016). For example, Arabidopsis mutants deficient in PG synthesis fail in thylakoid membrane formation (Babiychuk et al, 2003; Hagio et al, 2002; Haselier et al, 2010; Kobayashi et al, 2015). Extracellular PG secreted by type II alveolar cells participates in regulation of innate immune response within the lung and in prevention of viral infections (Hallman et al, 1985; Kandasamy et al, 2011; Numata et al, 2010, 2012, 2013). And, a product of PG degradation, diacylglycerol, is an important signaling molecule (Roelants et al, 2017; Stahelin et al, 2004).

In yeast, PG is a low-abundant phospholipid. It is biosynthesized in the inner mitochondrial membrane (Schlame \& Haldar, 1993) and either utilized as substrate by the cardiolipin synthase (Crd1) (Chang et al, 1998b; Jiang et al, 1997; Tuller et al, 1998) or degraded by a PG-specific phospholipase C (Pgc1) (Pokorná et al, 2015; Simocková et al, 2008). The cellular level of PG is subject of tight regulation, and its misbalance influences deleteriously various cell functions. Cells lacking the phosphatidylglycerolphosphate synthase Pgs1, an enzyme responsible for the rate-limiting step of PG synthesis, lack both PG and cardiolipin. These cells fail to grow on nonfermentable carbon sources, are heat-sensitive (Chang et al, 1998a), and their mitochondria contain extremely elongated cristae sheets, which frequently form onion-like structures (Connerth et al, 2012). Mutants accumulating PG exhibit weaker, but still significant phenotypes. Cells lacking Crd1 accumulate PG in the absence of cardiolipin. Accordingly, most of their abnormal features, such as compromised stability of respiratory supercomplexes and mitochondrial DNA or decreased mitochondrial potential, result rather from the absence of CL than from the excess of PG (Baile et al, 2014; Jiang et al, 2000; Luévano-Martínez et al, 2015; Pfeiffer et al, 2003; Zhang et al, 2002; Zhong et al, 2004). However, phenotype differences 
between pgs $1 \Delta$ and $\operatorname{crd} 1 \Delta$ strains, which both lack cardiolipin but contain different amounts of PG, suggest specific roles for PG as well. These roles could be directly identified in a pgcls strain, which accumulates PG without significant changes in the other phospholipids (Simocková et al, 2008). Cells lacking the PGCl gene exhibit fragmented mitochondrial network and increased respiration rates due to elevated activity of cytochrome $c$ oxidase (Pokorná et al, 2015).

The subcellular localization of the two enzymes depleting the limited cellular stocks of PG, Crd1 and Pgc1, strongly differ. While Crd1 activity has been localized exclusively to the inner mitochondrial membrane (Schlame \& Haldar, 1993), the distribution of Pgc1 protein was confined to lipid droplets (LD), as reported by cell-fractionation and fluorescence microscopy data (Beilharz et al, 2003; Currie et al, 2014; Grillitsch et al, 2011; Ruggiano et al, 2016; Simocková et al, 2008). LD are universally conserved dynamic organelles, which exhibit a unique topology consisting of a hydrophobic core, predominantly composed of triacylglycerol and sterol esters, coated by a phospholipid monolayer and a set of specific proteins. The primary functions of LD are the storage of lipids and protection against lipotoxicity (Garbarino et al, 2009; Valachovic et al, 2016; Korber et al, 2017). However, more functions of LD were discovered, including an involvement in cellular signaling, lipid trafficking, protein storage, autophagy, and sporulation (Barbosa et al, 2015; Daum et al, 2007; Hsu et al, 2016; Leber et al, 1998; Singh et al, 2009; Wang, 2014, 2015).

In this study, we address the role of LD in the homeostasis of PG - the anionic lipid synthesized in mitochondria. We show that the absence of the LD protein, PG specific phospholipase Pgc1, causes spreading of PG over various cellular membranes. Together with in vitro tests of Pgc1 activity, our data suggest that the enzyme is inactive at the surface of LD and gets activated only after the translocation to intracellular membranes. Consequently not LD, but rather membranes of the neighboring organelles (endoplasmic reticulum (ER) and mitochondria) host the PG degradation. In this model, LD serve as storage places for the Pgc1 enzyme allowing for effective regulation of $\mathrm{PG}$ levels. 


\section{Results}

PG-specific phospholipase Pgc1 localizes exclusively to LD

Various analyses localized Pgc1 to LD (Beilharz et al, 2003; Simocková et al, 2008; Grillitsch et al, 2011; Currie et al, 2014), and mitochondria (Sickmann et al, 2003). Fluorescently tagged Pgc1 was shown to accumulate exclusively in LD when yeast cells were grown in the rich medium (Ruggiano et al, 2016). We checked to what extent this localization pattern of Pgc1 depends on the levels of the Pgc1 substrate, PG. To visualize the subcellular distribution of the Pgc1 protein, we prepared strains expressing a GFP-tagged version of Pgc1. The specific phenotype of a pgc1s mutant, namely accumulation of increased cellular PG levels in inositolfree media (Simockova et al., 2008), was successfully complemented by the expression of GFP$\mathrm{Pgc} 1$, indicating the functionality of the fusion protein (Fig EV1).

Inositol is a known repressor of PG biosynthesis (He \& Greenberg, 2004; Zhong \& Greenberg, 2003). Even in inositol-free medium, however, the vast majority of the GFP-Pgc1 fluorescence signal in pgc1 1 cells expressing the GFP-Pgc1 fusion was confined to the surface of LD (Fig 1). Non-uniformly sized bright spots or empty circles of the GFP-Pgc1 fluorescence, as visualized in individual confocal sections, were unequivocally identified with LD using the specific lipophilic marker LD540 (Fig 2A-D). FRAP analysis revealed a stable character of this distribution: only slow recovery of the fluorescence intensity with the half-time of $704 \pm 21 \mathrm{~s}$ was observed after photobleaching of the GFP-Pgc1 fluorescence signal corresponding to an individual LD (Fig $2 \mathrm{E})$. The quasi-linear character of the recovery curve indicated a limited communication between individual LD.

A similar experiment was performed in the pgc1s mutant of a strain defective in LD formation

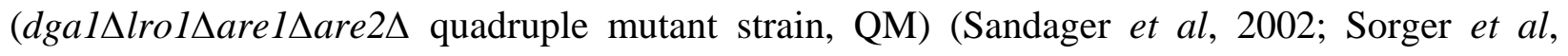
2004; Athenstaedt, 2011). This scenario resulted in a completely different localization pattern of GFP-Pgc1. In QMpgc1s cells, the entire signal of the GFP-Pgc1 fluorescence was evenly distributed in membranes of the ER (Fig 2F, G). In contrast to GFP-Pgc1 localized in LD in the pgc1 1 strain, GFP-Pgc1 at perinuclear and cortical ER of the QMpgc1 $\Delta$ cells was highly mobile. Fluorescence recovery half-time was estimated to $3.1 \pm 1.2 \mathrm{~s}$, with the mobile fraction of $71 \pm 9 \%$ (Fig 2H). 


\section{Deletion of the PGC1 gene causes accumulation of specific PG pools in various organelles}

To address the subcellular localization of Pgc1 phospholipase activity in situ, we monitored the changes in the lipid composition of internal membranes caused by the deletion of $P G C 1$. We expected PG to accumulate in those membranes of the pgcls mutant, which in wild type strain represent either the places where the PG degradation is localized or at least places which communicate with places of PG degradation. Another strain showing the elevated levels of PG, $\operatorname{crdl\Delta }$, was used as a control to verify that the changes observed in $\operatorname{pgcl\Delta }$ cells represented specific consequences of the $P G C 1$ deletion.

First, we analyzed the relative PG abundance in LD, mitochondrial and ER fractions of the wild type, $p g c 1 \Delta$ and $\operatorname{crd} 1 \Delta$ cells (see Materials and Methods for details). Compared to the wild type, the relative abundance of PG was increased in all the analyzed subcellular fractions of the $p g c 1 \Delta$ mutant. No significant difference among LD, mitochondrial and ER membrane fraction could be seen; in all the fractions, PG levels represented $\sim 4.5 \%$ of the total phospholipids (Fig 3A). In contrast, accumulation of PG in $\operatorname{crdl} \Delta$ cells occurred almost exclusively in mitochondria, which exhibited a PG level of $8.6 \pm 1.1 \%$ of total phospholipids, while levels below $1 \%$ were detected in the LD and ER fractions of $c r d 1 \Delta$ membranes.

Next, we compared the fatty acid composition of PG in the mitochondrial and the ER fraction of pgc1D. As shown in Fig 3B, no detectable difference between the two fractions could be identified, which indicated free PG exchange between ER and mitochondria. Both samples exhibited a significantly increased fraction of palmitoleic acid compared to the PG extracted from wild type mitochondria. Importantly, increased oleate instead of palmitoleic acid level was observed in mitochondrial membranes of $\operatorname{crd} 1 \Delta$ cells. It is noteworthy that the acyl chain composition itself does not determine the Pgc1 phospholipase selectivity. As we showed previously, PG accumulated in mitochondrial membranes of $\operatorname{crd} 1 \Delta$ cells could not be hydrolyzed by Pgc1 in situ, but it was accepted as a Pgc1 substrate in vitro (Pokorná et al, 2015). Altogether, these results could not indicate a specific localization of Pgc1 activity - all the analyzed fractions of pgcls membranes exhibited similar abundance and acyl chain composition of the accumulated PG.

Localization to a lipid bilayer is prerequisite for the enzymatic activity of Pgcl protein 
To directly test which organelle hosts the PG degradation, we analyzed in vitro activity of Pgc1 phospholipase in isolated membrane fractions. LD, mitochondrial and ER fractions were incubated with a fluorescent Pgc1 substrate (NBD-PG), and hydrolysis of this substrate to a fluorescent product (NBD-DAG) with altered thin layer chromatography mobility was used to measure Pgc1 activity in each fraction (Simocková et al, 2008).

In most of the analyzed strains, we observed $\sim 50 \%$ hydrolysis of NBD-PG by Pgc1 in cell homogenates (Fig 4A). Comparable Pgc1 activities detected in wild type and QM mutant cells indicated that the presence of $\mathrm{LD}$, the compartment accumulating the vast majority of Pgc1 in the wild type cells (Fig 2A-D), was not critical for PG degradation. This observation was further supported by the fact that the QM cells lacking LD did not exhibit elevated PG levels compared to the wild type (Fig EV2). Only low levels of NBD-PG hydrolysis were detected in all three analyzed sub-cellular fractions of wild type cells. Surprisingly, the highest NBD-DAG signal was detected in the ER fraction, while the Pgc1-enriched LD fraction of wild type cells exhibited no significant in vitro phospholipase activity.

Ruggiano and co-workers reported decreased degradation of $\mathrm{Pgc1}$ protein in the strain lacking ubiquitin-protein ligase Doa10 (Ruggiano et al, 2016). Accordingly, we detected higher levels of Pgc1 activity in both ER and mitochondrial membrane fractions of doal0s strain compared to wild type. We observed similar increase of Pgc1 activity in a mutant strain lacking the mitochondrial outer membrane protein Msp1 that is also involved in protein quality control (Chen et al, 2014; Okreglak \& Walter, 2014). However, the highest Pgc1 activity was detected in QM cells where all Pgc1 localized to membranes (predominantly to the ER membrane, Fig 2F, G). High Pgc1 activity was observed in both ER and mitochondrial fractions of QM cells, which indicated that not only the substrate (PG), but also the enzyme (Pgc1) can be exchanged between these two compartments. As apparent from the control experiments performed in pgcl $\Delta$,

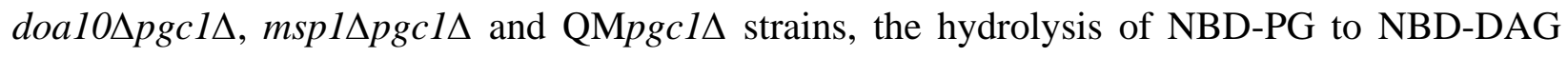
could be ascribed predominantly to the activity of Pgc1 (Fig 4A).

It is worth mentioning that the observed absence of Pgc1 activity in LD did not reflect the absence of the substrate - LD of pgcls cells accumulated PG at levels similar to ER and mitochondrial membranes (Fig 3). Similarly, when NBD-PG was added to the LD fraction, it also massively associated with LD (Fig EV3). As an alternative explanation for the negligible 
NBD-PG hydrolysis in LD fraction of the wild type cells, we tested the hypothesis that Pgc1 activation required embedding of the enzyme into the phospholipid bilayer.

To confirm that the inability of Pgc1 to hydrolyze PG in the phospholipid monolayer of the LD surface (Figs 1,2) can explain the results presented in Fig 4A, we measured in vitro Pgc1 activity in mixtures of the LD fraction with different membranes. Three types of Pgc1-less membranes were used: ER or mitochondrial fractions isolated from pgcls cells, liposomes prepared from lipids isolated from these two fractions of $\mathrm{pgcl \Delta}$ cells, and liposomes prepared from synthetic phospholipids (PC/PE, 3:1). In any of these membrane samples, no measurable spontaneous hydrolysis of NBD-PG could be detected. After the addition of the LD fraction isolated from wild type cells that contained Pgc1, we observed a clear increase of the NBD-PG hydrolysis product, NBD-DAG. This increase strongly depended on the Pgc1 protein content in the added LD fraction (Fig 4B). In LD-containing mixtures, either with complete ER or mitochondrial membrane fractions or with reconstituted bilayers from the respective extracted lipids, comparable amounts of NBD-DAG were detected. Lower, but significant NBD-PG hydrolysis was detected even in a mixture with liposomes prepared from synthetic lipids (Fig 4C). Apparently, the presence of a phospholipid bilayer was sufficient to induce the phospholipase C activity of Pgc1.

Another support for the hypothesis that the phospholipase activity of Pgc1 required the enzyme embedded into a lipid bilayer was provided by the analysis of in vitro Pgc1 activity in cell homogenates prepared from wild type and QM strains. For each strain, we compared Pgc1 activities in homogenates prepared by two different approaches. In the first approach, the cells were disintegrated with glass beads. This approach results in a high fragmentation of all cellular contents, including membranes. The second, gentler approach represented enzymatic cell wall digestion by zymolyase followed by breaking the cells in a Dounce homogenizer. In this case, the membrane fragmentation is significantly lower, this approach even preserves mitochondrial membrane respiration (Pokorná et al, 2015). Our data clearly indicated that the in vitro Pgc1 activity was significantly higher in gently prepared cell homogenates, which contained better preserved membranes. The detected difference in Pgc1 activity was about 2-fold in wild type, and about 5-fold in QM mutant preparations (Fig EV4). Concerning the difference between wild type and QM samples homogenized with beads, relatively higher Pgc1 activity detected in wild 
type cells could indicate an unspecific spreading of the Pgc1 protein from LD disintegrated during the treatment.

Since Ruggiano et al. (2016) suggested that the C-terminal domain of Pgc1 could be responsible for the membrane association of the enzyme, we tested localization and phospholipase activity of the C-terminally truncated Pgc1 proteins, $\mathrm{Pgc} 1^{1-274}$ and $\mathrm{Pgc} 1^{1-297}$. The expression level of Pgc1 constructs from plasmid was confirmed by RT-qPCR of the specific mRNA, and it was about 50fold higher compared to the expression of genomic PGCl in the wild type (Fig 5A). In the case of GFP-Pgc1 proteins, Western blot quantification of the protein level was performed. In $\mathrm{pgcl \Delta}$ and QMpgc1 $\Delta$ cells, it showed low levels of both C-terminal truncated proteins GFP-Pgc1 $1^{1-274}$ and GFP-Pgc1 ${ }^{1-297}$ compared to full-length GFP-Pgc1 (Fig 5B). This corresponded well with our fluorescence microscopy observations: in cells expressing the GFP-Pgc $1^{1-274}$ protein, just a faint GFP fluorescence homogenously dispersed in cytoplasm and none localized to LD could be detected (Fig 5C). As revealed by the in vitro NBD-PG assay, phospholipase $\mathrm{C}$ activities present in homogenates of cells expressing only truncated Pgc1 proteins, $\mathrm{Pgc1}^{1-274}$ and $\mathrm{Pgc} 1^{1-297}$, were an order of magnitude lower compared to the full-length protein (Fig 5D). These reduced activities also reflect primarily low levels of truncated proteins in homogenates, although they also indicate the persisting enzymatic activity of the C-terminally truncated Pgc1 proteins. However, overexpression of none of the truncated proteins was able to fully complement the most prominent pgcl $1 \Delta$ phenotype - accumulation of PG (Fig 5E). Together with the aforementioned data, these results strongly supported our hypothesis that embedding of the Pgc1 protein into the phospholipid bilayer was prerequisite for its phospholipase activity. 


\section{Discussion}

While the biosynthesis of mitochondrial anionic phospholipids was clearly localized to the inner mitochondrial membrane (Schlame \& Haldar, 1993; Dzugasová et al, 1998), little is known about subcellular localization of their degradation. Specifically, limited knowledge is available concerning the mechanisms by which relatively low concentrations of these lipids are maintained outside mitochondria. In this study, we tried to address this problem by the analysis of the enzymatic activity of a yeast PG-specific phospholipase C Pgc1 within the cell.

Under normal conditions, Pgc1 enzyme localizes exclusively to LD (Fig 1, see also (Simocková et al, 2008; Beilharz et al, 2003; Grillitsch et al, 2011; Ruggiano et al, 2016; Currie et al, 2014)), and as indicated by our FRAP data, its availability outside this compartment is strongly limited (Fig 2E). This localization pattern of Pgc1 is insensitive to the stimulation of PG biosynthesis in the absence of inositol (Fig 1). Even under the conditions of induced PG biosynthesis, LDconfined Pgc1 is capable to prevent PG accumulation in various locations - in the ER, mitochondrial and probably also in other membranes (Fig 3A). This fact indicates ongoing phospholipase activity of Pgc1 under these conditions.

The activity of Pgc1 however is independent on the LD compartment, as we detected comparable levels of PG degradation in wild type and QM strain, which is defective in LD formation (Fig EV2). Moreover, no phospholipase activity of Pgc1 could be detected in isolated Pgc1containing LD fraction, suggesting that the Pgc1-mediated PG degradation occurs outside LD. Similar dual localization of the active and inactive enzyme has been documented before. Enzymatic activity of another LD protein, squalene epoxidase Erg1, takes place at the ER membrane. In contrast to Pgc1 however, partitioning of Erg1 to both LD and the ER membrane could be clearly visualized by fluorescence microscopy in wild type cells (Leber et al, 1998).

Not all PG outside LD is accessible for Pgc1-mediated degradation. For example, Pgc1 failed to remove PG accumulated in crdl $\Delta$ mutant. We suggested recently that this was probably due to the specific localization of the PG pool in crdlA cells (Pokorná et al, 2015). Data presented in Fig 3A strongly support this hypothesis, documenting a specific distribution of PG in $\operatorname{crdl\Delta }$ cells. While rather homogenous spreading of PG over all analyzed cellular fractions could be observed in pgcl $\Delta$ cells, the crdl $\Delta$ mutant stored a high amount of PG only in mitochondria. 
Moreover, PG accumulating in crdl 14 mutant exhibited a significant difference in acyl chain composition, if compared to PG accumulated by pgclA cells (Fig 3B). This finding suggested that mitochondrial PG in $\mathrm{crdl} 1 \Delta$ cells could be a subject of remodeling, similar to CL in the wild type. Finally, PG accumulated by the crd1 $1 \Delta$ mutant could be hydrolyzed by Pgc1 in vitro (Pokorná et al, 2015), indicating that not the acyl chain composition, but the localization of the lipid in these cells interferes with the Pgc1 function. We speculate that the observed difference in acyl chain composition, as well as enormous stability towards Pgc1-mediated degradation in situ (Pokorná et al, 2015) could reflect the fact that in crd1 cells, PG functionally substitutes the missing CL at the inner mitochondrial membrane.

Several lines of evidence indicate that the phospholipase activity of Pgc1 is not strictly determined by the composition of the surrounding membrane, but rather by the embedding of the protein into a lipid bilayer: i) while Pgc1 was inactive in pure LD fractions, it was capable to hydrolyze NBD-PG in our in vitro assay when a bilayer membrane was added to the reaction. This effect was similar whether biological membranes or just lipid membranes composed of isolated or synthetic lipids were used (Fig 4C); ii) phospholipase activity of Pgc1 in cell homogenates depended on the presence of intact membranes rather than on the original distribution of the Pgc1 protein in situ (Fig EV4); iii) phospholipase activity of C-terminally truncated Pgc1 proteins, which contained the whole glycerophosphodiester phosphodiesterase motif (Simocková et al, 2008), but lacked membrane localization domains, was effectively suppressed (Fig 5). Together these data suggest that the spatial sequestration of Pgc1 in a surface lipid monolayer of LD provides two independent ways to regulate the Pgc1 activity: 1) direct inhibition of the phospholipase function by keeping the protein outside the lipid bilayer, probably in a conformation which precludes its phospholipase activity, and 2) indirect inhibition by a strong limitation of the protein exchange between LD surface and membranes (Fig 2E).

Based on these data, we suggest a model of PG homeostasis mediated by the Pgc1 activity, which is tightly regulated by the localization and a rapid turnover of the enzyme (Fig 6). In this model, PG is generated at the inner mitochondrial membrane. The portion of the lipid which is not used for the CL biosynthesis freely spreads to other membranes within the cell along the concentration gradient. In these membranes, PG is cleaved by a specific phospholipase, Pgc1. Pgc1 seems to be a very effective enzyme, as just a minute in fluorescence microscopy invisible 
fraction of this protein is sufficient to keep PG at low level. But not lower than necessary: Pgc1 itself is a subject to fast degradation, executed by Ssm4/Doa10 ubiquitin-protein ligase at the ER membrane, and possibly by Msp1 AAA-ATPase at the outer mitochondrial membrane (Fig 4A; Ruggiano et al, 2016). Indeed, there are indications that $\mathrm{Pgc1}$ can migrate to the outer mitochondrial membrane, at least under the conditions of overexpression (Simocková et al, 2008), or in the absence of LD (Fig 4A). Under normal conditions, LD provide a storage place for the vast majority of $\mathrm{Pgc1}$. Localization to LD protects the protein against ubiquitination and the rapid turnover. Delivery of Pgc1 to the ER membrane is mediated by continuous LD-ER contacts; direct contacts of LD with other membranes are not a priori excluded either.

The described arrangement represents an effective mechanism capable of fast, wide-range, and bidirectional regulation of PG levels within the cell. What remains to be answered is the reason why the cells so tightly control the content of one minor phospholipid in their membranes, as apparently too low, as well as too high amounts of PG matter. So far, only a few indications are available in this respect. We know, for example, that the accumulation of PG compromises the barrier function of the inner mitochondrial membrane in pgcl $\Delta$ cells (Pokorná et al, 2015). In $C$. elegans, changes in mitochondrial morphology triggered after inactivation of CL synthase were recently also interpreted in terms of PG accumulation rather than lack of CL (Matsumura et al, 2018). Also, it is worth mentioning that the product of PG hydrolysis, DAG, is an important signaling molecule (Roelants et al, 2017; Stahelin et al, 2004). Further studies will be necessary to explain the specific roles of PG in the membrane system of eukaryotic cells.

\section{Materials and Methods}

\section{Yeast strains and growth conditions}

All yeast strains used in this study are listed in Table 1. Cultures were grown on complex media YPD (2\% yeast extract, $1 \%$ peptone, $2 \%$ glucose). For experiments, yeast were grown aerobically at $30{ }^{\circ} \mathrm{C}$ in a defined synthetic SMD medium prepared as described previously (Griac et al, 1996), with $2 \%$ glucose as a carbon source. Synthetic medium was either supplemented with $75 \mu \mathrm{M}$ inositol (I+) or lacked inositol (I-). Transformants were selected on synthetic medium without uracil or histidine. 


\section{Plasmids and strains construction}

Tetracycline-regulated centromeric expression vector pCM189 (Euroscarf, Scientific Research and Development GmbH, Germany) was used for the expression of PGCl genes. To prepare pCM189-PGC1 plasmid, the PGC1 gene was amplified by PCR from S. cerevisiae genomic DNA using 5'-ATCAGGATCCATGGTTGAAATTGTGGGCCAC-3' and 5'AGAGCTGCAGCAAAATATCACTATTCAAATCTCGC-3'primers. The PCR fragment was then ligated into pCM189 plasmid using BamHI and PstI restriction sites.

To prepare pCM189-GFP-PGC1 plasmid, the GFP gene was amplified by PCR from the plasmid used before (Beilharz et al, 2003) using 5'ATtGGATCCCGGGATGAGTAAAGGAGAAGAACTTTTCAC-3' ' and 5'ATTGGATCCCTGCAGTTTGTATAGTTCATCCATGCCAT-3' primers. The amplified PCR fragment was digested with BamHI and cloned into the BamHI restriction site of the pCM189$P G C 1$ plasmid. Both truncated versions of $P G C 1$ or $G F P-P G C 1$ were prepared by amplifying with the same forward 5, primer, for $P G C 1$ versions (5'ATCAGGATCCATGGTTGAAATTGTGGGCCAC-3') and for GFP-PGC1 versions 5'ATTGGATCCCGGGATGAGTAAAGGAGAAGAACTTTTCAC-3'). Reverse primer 5'ATTGCGGCCGCTCATACAGATGCCAGACTGGGCG-3' was used for amplifying $P G C 1^{1-274}$ or GFP-PGC1 $1^{1-274}$, and 5'- ATTGCGGCCGCTCACCATTTGGAATATAGAAGCGT-3' was used for amplifying $P G C 1^{1-297}$ or $G F P-P G C 1^{1-297}$ by PCR from pCM189-GFP-PGC1. The PCR fragments were then ligated into pCM189 plasmid using BamHI and NotI restriction sites.

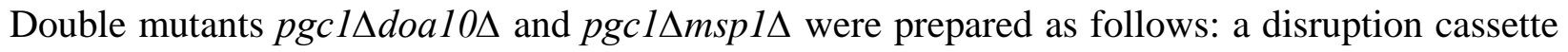

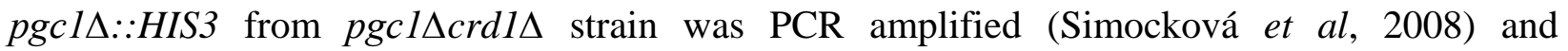

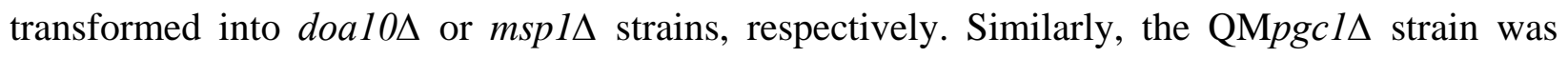
prepared. Yeast transformation was performed by the lithium acetate method (Gietz \& Woods, 2002).

Fluorescence Microscopy 
Living yeast cells grown in SMD I- or SMD I+ medium were concentrated by brief centrifugation, immobilized on a $0.17 \mathrm{~mm}$ thick coverslip by a thin film of $1 \%$ agarose in 50 $\mathrm{mM}$ phosphate buffer, $\mathrm{pH}$ 6.3, and observed using a confocal microscope LSM510 (Zeiss) with a 100× PlanApochromat oil-immersion objective (NA = 1.4). Fluorescence signals of GFP and LD540 (a generous gift of Dr. Christoph Thiele, Max Planck Institute of Molecular Cell Biology and Genetics, Dresden, Germany) were excited by $488 \mathrm{~nm}$ line of Ar laser and $561 \mathrm{~nm}$ line of solid state laser, and detected using bandpass 505-550 and 575-615 nm emission filters, respectively. For staining with LD540, the dye dissolved in ethanol was added to the cell culture (to final dye concentration of $0.5 \mu \mathrm{g} / \mathrm{ml}$ ) and incubated in dark at the room temperature for 30 $\min$.

\section{Fluorescence recovery after photobleaching}

Fluorescence recovery after photobleaching (FRAP) experiments were performed in the single photon excitation mode on the laser scanning microscope FV1200MPE (Olympus) with a 100× PlanApochromat oil-immersion objective $(\mathrm{NA}=1.4)$. Fluorescence signal of GFP was excited by $488 \mathrm{~nm}$ line of Ar laser, and detected using a bandpass 500-545 nm emission filter. A SIM scanner was used to minimize the time delay between the fluorescence photobleaching in the region of interest (ROI) and the acquisition of the first post-bleach frame. To quantify the initial level of fluorescence, five $x-y$ frames were acquired prior to the bleaching. Circular ROI encompassing a whole individual LD or a part of the ER membrane, with a diameter of $1 \mu \mathrm{m}$, was bleached with $50 \mathrm{~ms}$ pulse of $405 \mathrm{~nm}$ laser at maximum intensity. The fluorescence recovery in LD and ER was monitored in 5 and $0.5 \mathrm{~s}$ intervals for 10 and 2 minutes, respectively. Acquired fluorescence intensities were corrected for the scan-induced photobleaching and normalized to the fluorescence intensity measured in a pre-bleach period. The curve fitting was performed in SigmaPlot 12.5 (Systat Software Inc.).

\section{Preparation of subcellular membranes}

Mitochondrial and ER fractions were isolated by differential centrifugation according to Zinser and Daum (Zinser \& Daum, 1995), with the following modifications: spheroplasts were prepared 
using Zymolyase 20T (Nacalai Tesque) from cells grown in SMD I- media for $24 \mathrm{~h}$ at $30{ }^{\circ} \mathrm{C}$. The spheroplasts were homogenized in a tight-fitting Dounce homogenizer in $0.6 \mathrm{M}$ mannitol; 10 $\mathrm{mM}$ Tris/ $\mathrm{HCl}, \mathrm{pH} 7.4 ; 1 \mathrm{mM}$ phenylmethylsulfonyl fluoride. The homogenate was centrifuged for $5 \mathrm{~min}$ at $3400 \mathrm{~g}$ to remove residual cell debris. The supernatant was centrifuged for $10 \mathrm{~min}$ at 11400 g. Next, supernatant from this centrifugation was used for isolation of ER and pellet for isolation of mitochondria. The pellet was washed with $0.6 \mathrm{M}$ mannitol; $10 \mathrm{mM}$ Tris/Cl, $\mathrm{pH} 7.4$, and the supernatant was centrifuged once at $17400 \mathrm{~g}$ and second time at $30000 \mathrm{~g}$ for $30 \mathrm{~min}$. The final pellet contained ER membranes. Both, mitochondria and ER fractions, were resuspended in $10 \mathrm{mM}$ Tris/ $\mathrm{HCl}, \mathrm{pH}$ 7.4. Purity of isolated fractions was checked with immunoblot of specific antibodies against relevant proteins localized to specific organelles.

\section{Phospholipid analysis}

Lipids were extracted from isolated fractions by modified Folch extraction using chloroform/methanol/HCl (60:30:0.26; v/v) (Folch et al, 1957). The remaining contaminants were removed by additional washing steps of the organic phase with $0.1 \% \mathrm{MgCl}_{2}$ solution (w/v). Individual phospholipids were separated by thin layer chromatography on Silica gel 60 plates (Merck) using chloroform/methanol/acetic acid developing solvent (65:25:8; v/v/v). Phospholipids were visualized on thin layer chromatography plates by staining with iodine vapor, scraped off and quantified as described (Broekhuyse, 1968), with slight modifications. Briefly, thin layer chromatography plate was moistened with ultra-pure water and each phospholipid spot was scraped off, put into a glass tube and dried in an oven at $105^{\circ} \mathrm{C}$. After cooling, $200 \mu \mathrm{l}$ of $\mathrm{H}_{2} \mathrm{SO}_{4} / \mathrm{HClO}_{4}(9: 1 ; \mathrm{v} / \mathrm{v})$ were added and the samples were incubated at $200{ }^{\circ} \mathrm{C}$ for $30 \mathrm{~min}$. The samples were cooled down at room temperature and then incubated with $4.8 \mathrm{ml}$ of $0.26 \%\left(\mathrm{NH}_{4}\right)_{6} \mathrm{Mo}_{7} \mathrm{O}_{24 .} 4 \mathrm{H}_{2} \mathrm{O}(\mathrm{w} / \mathrm{v}) /$ ANSA $\left(16 \% \mathrm{~K}_{2} \mathrm{~S}_{2} \mathrm{O}_{5} ; 0.252 \% \mathrm{C}_{10} \mathrm{H}_{9} \mathrm{NO}_{4} \mathrm{~S} ; 0.5 \%\right.$ $\left.\mathrm{Na}_{2} \mathrm{SO}_{3} ; \mathrm{w} / \mathrm{v}\right)$ at a ratio of $250: 11(\mathrm{v} / \mathrm{v})$ at $105{ }^{\circ} \mathrm{C}$ for other $30 \mathrm{~min}$. After incubation, samples were cooled down, vortexed, and the silicagel was gently spun down at $500 \mathrm{~g}$ for $2 \mathrm{~min}$. Phosphate $\left(\mathrm{P}_{\mathrm{i}}\right)$ of phospholipids reacts with Ammonium Heptamolybdate forming molybdenum blue, the concentration of which was assessed by absorption spectrometry at $830 \mathrm{~nm}$. 


\section{Measurements of Pgcl activity in vitro}

Pgc1 activity was measured as described previously (Simocková et al, 2008): in vitro reaction of final volume $240 \mu \mathrm{l}$ contained $40 \mu \mathrm{l}$ of $0.3 \mathrm{M}$ Tris/HCl, $\mathrm{pH} 7.4 ; 20 \mu \mathrm{l}$ of NBD-PG $(0.8 \mu \mathrm{g})$ in $0.1 \%$ Triton $\mathrm{X}-100$, and isolated subcellular fraction with defined amounts of proteins (LD fraction - $20 \mu \mathrm{g}$ of proteins, other fractions - $175 \mu \mathrm{g}$ of proteins) or a defined volume of liposomes (adequate for $200 \mu \mathrm{g}$ of proteins of relevant cellular fraction, or $150 \mu \mathrm{l}$ of buffered synthetic liposomes, see below). The mixture was incubated at $30^{\circ} \mathrm{C}$ for $40 \mathrm{~min}$. The reaction was stopped by the addition of chloroform/methanol/HCl $(2 \mathrm{ml} ; 100: 100: 0.6 \mathrm{v} / \mathrm{v} / \mathrm{v})$ and $1 \mathrm{ml}$ of water. After the separation, the organic phase was dried under a stream of nitrogen. NBD-labeled lipids were separated by one-dimensional thin layer chromatography for 17 min using chloroform/methanol/28\% ammonium hydroxide developing solvent (65:35:5; v/v/v). Separated NBD-lipids were scanned with a TLC Scanner (Camag) in the fluorescence mode at wavelength $460 \mathrm{~nm}$ and phospholipase activity of Pgc1 was determined as a fraction of NBD-DAG, product of NBD-PG hydrolysis, in total NBD-lipids. Mixtures of LD (isolated from WT, pgc1 $\Delta$ or pgc1 $1 \Delta+P G C 1$ cells) with various membrane bilayers (isolated from mitochondria or ER from pgc $1 \Delta$ cells) were incubated at $30^{\circ} \mathrm{C}$ on a shaker for $30 \mathrm{~min}$.

\section{Preparation of liposomes}

Liposomes were prepared either from phospholipids extracted from organelle fractions or from synthetic phospholipids (Avanti Polar Lipids). After evaporation of organic solvents under the stream of nitrogen, lipids extracted from isolated mitochondrial or ER fractions were buffered with $10 \mathrm{mM}$ Tris/ $\mathrm{HCl}, \mathrm{pH} \mathrm{7.4,} \mathrm{and} \mathrm{left} \mathrm{at} \mathrm{room} \mathrm{temperature} \mathrm{for} \mathrm{one} \mathrm{hour.} \mathrm{Then,} \mathrm{the} \mathrm{suspension}$ was sonicated (5 minutes) until it became transparent. In preparation of synthetic liposomes, 1,2dipalmitoyl-sn-glycero-3-phosphocholine and 1-palmitoyl-2-oleoyl-sn-3-phosphoethanolamine (3:1; Avanti Polar Lipids) were dissolved in chloroform, which was evaporated under the stream of nitrogen. $10 \mathrm{mM}$ Tris/ $\mathrm{HCl}, \mathrm{pH} 7.4$ was added to a final concentration of phospholipids at 6.5 $\mathrm{mM}$. Buffered lipids were incubated at $60{ }^{\circ} \mathrm{C}$ with occasional vortexing for $3-4 \mathrm{~h}$. Then, the suspension was sonicated ( 5 minutes) until it became transparent. The final concentration of phospholipids was $4.1 \mathrm{mM}$. 


\section{Immunoblotting}

Proteins obtained from cell homogenates $(100 \mu \mathrm{g})$ were separated on $12 \%$ SDS polyacrylamide gels and blotted onto a nitrocellulose membrane. The membrane was blocked using 5\% dry milk in TBS buffer (50 mM Tris/HCl, pH 8.0; $150 \mathrm{mM} \mathrm{NaCl} ; 0.05 \%$ Tween 20 (v/v)) overnight. Then, the membrane was immunostained using the following antibodies: polyclonal rabbit antiGFP (Abcam, Cambridge, UK; dilution 1:1000); and rabbit anti-Por1 (1:1000). Visualization of secondary anti-rabbit (Sigma-Aldrich) antibodies was done using the Amersham ECL+ kit (GE Healthcare Life Sciences).

\section{Miscellaneous}

Analysis of fatty acids, RNA isolation, RT-qPCR analysis (Pokorná et al, 2015) and isolation of LD fraction (Grillitsch et al, 2011) were performed as described previously. Statistical comparisons were carried out by one-way analysis of variance using SigmaPlot 12.5 software (Systat Software Inc.). All graphs show the mean \pm SEM.

\section{Acknowledgements}

We thank Marta Kostolanská, Petronela Melicherová and Katarína Nagyová for technical help. We are also grateful to Ivan Hapala for careful reading of the manuscript and stimulating comments. The work was supported by Scientific Grant Agency of the Ministry of Education, Science, Research and Sport of the Slovak Republic and the Slovak Academy of Sciences 2/0168/14 and 2/0165/18, the Slovak Research and Development Agency contracts APVV-150654, AS CR \& SAV Joint Project SAV-18-25 and Slovak Academy of Sciences (SAS-MOST JRP 2016/4). It is a result of the "Advanced Bioimaging of Living Tissues" project, reg. $n$. CZ.2.16/3.1.00/21527, which was financed from the budget of the European Regional Development Fund and public budgets of the Czech Republic through the Operational Programme Prague - Competitiveness. Günter Daum was supported by the Austrian Science Fund (FWF). 


\section{Author contributions}

MB and DK designed and performed most of the experiments and analyzed the data. JM and TA designed and performed the FRAP experiments. JM and PV performed fluorescence microscopy localizations. MB and JM wrote the manuscript with input from GD. All authors discussed the results.

\section{Conflict of interest}

The authors declare that they have no conflict of interest.

\section{References}

Athenstaedt K (2011) YALIOE32769g (DGA1) and YALIOE16797g (LRO1) encode major triacylglycerol synthases of the oleaginous yeast Yarrowia lipolytica. Biochim. Biophys. Acta 1811: 587-596

Babiychuk E, Müller F, Eubel H, Braun H-P, Frentzen M \& Kushnir S (2003) Arabidopsis phosphatidylglycerophosphate synthase 1 is essential for chloroplast differentiation, but is dispensable for mitochondrial function. Plant J. 33: 899-909

Baile MG, Sathappa M, Lu Y-W, Pryce E, Whited K, McCaffery JM, Han X, Alder NN \& Claypool SM (2014) Unremodeled and remodeled cardiolipin are functionally indistinguishable in yeast. J. Biol. Chem. 289: 1768-1778

Barbosa AD, Savage DB \& Siniossoglou S (2015) Lipid droplet-organelle interactions: emerging roles in lipid metabolism. Curr. Opin. Cell Biol. 35: 91-97

Beilharz T, Egan B, Silver PA, Hofmann K \& Lithgow T (2003) Bipartite signals mediate subcellular targeting of tail-anchored membrane proteins in Saccharomyces cerevisiae. J. Biol. Chem. 278: 8219-8223

Broekhuyse RM (1968) Phospholipids in tissues of the eye. I. Isolation, characterization and quantitative analysis by two-dimensional thin-layer chromatography of diacyl and vinyl-ether phospholipids. Biochim. Biophys. Acta 152: 307-315

Chang SC, Heacock PN, Clancey CJ \& Dowhan W (1998a) The PEL1 gene (renamed PGS1) encodes the phosphatidylglycero-phosphate synthase of Saccharomyces cerevisiae. J. Biol. Chem. 273: 98299836

Chang SC, Heacock PN, Mileykovskaya E, Voelker DR \& Dowhan W (1998b) Isolation and characterization of the gene (CLS1) encoding cardiolipin synthase in Saccharomyces cerevisiae. J. Biol. Chem. 273: 14933-14941

Chen Y-C, Umanah GKE, Dephoure N, Andrabi SA, Gygi SP, Dawson TM, Dawson VL \& Rutter J (2014) Msp1/ATAD1 maintains mitochondrial function by facilitating the degradation of mislocalized tailanchored proteins. EMBO J. 33: 1548-1564 
Connerth M, Tatsuta T, Haag M, Klecker T, Westermann B \& Langer T (2012) Intramitochondrial Transport of Phosphatidic Acid in Yeast by a Lipid Transfer Protein. Science 338: 815-818

Currie E, Guo X, Christiano R, Chitraju C, Kory N, Harrison K, Haas J, Walther TC \& Farese RV (2014) High confidence proteomic analysis of yeast LDs identifies additional droplet proteins and reveals connections to dolichol synthesis and sterol acetylation. J. Lipid Res. 55: 1465-1477

Daum G, Wagner A, Czabany T \& Athenstaedt K (2007) Dynamics of neutral lipid storage and mobilization in yeast. Biochimie 89: 243-248

Dzugasová V, Obernauerová M, Horváthová K, Vachová M, Záková M \& Subík J (1998) Phosphatidylglycerolphosphate synthase encoded by the PEL1/PGS1 gene in Saccharomyces cerevisiae is localized in mitochondria and its expression is regulated by phospholipid precursors. Curr. Genet. 34: 297-302

Folch J, Lees M \& Sloane Stanley GH (1957) A simple method for the isolation and purification of total lipides from animal tissues. J. Biol. Chem. 226: 497-509

Garbarino J, Padamsee M, Wilcox L, Oelkers PM, D’Ambrosio D, Ruggles KV, Ramsey N, Jabado O, Turkish A \& Sturley SL (2009) Sterol and diacylglycerol acyltransferase deficiency triggers fatty acidmediated cell death. J. Biol. Chem. 284: 30994-31005

Gietz RD \& Woods RA (2002) Transformation of yeast by lithium acetate/single-stranded carrier DNA/polyethylene glycol method. Methods Enzymol. 350: 87-96

Griac P, Swede MJ \& Henry SA (1996) The role of phosphatidylcholine biosynthesis in the regulation of the INO1 gene of yeast. J. Biol. Chem. 271: 25692-25698

Grillitsch K, Connerth M, Köfeler H, Arrey TN, Rietschel B, Wagner B, Karas M \& Daum G (2011) Lipid particles/droplets of the yeast Saccharomyces cerevisiae revisited: lipidome meets proteome. Biochim. Biophys. Acta 1811: 1165-1176

Hagio M, Sakurai I, Sato S, Kato T, Tabata S \& Wada H (2002) Phosphatidylglycerol is Essential for the Development of Thylakoid Membranes in Arabidopsis thaliana. Plant Cell Physiol. 43: 1456-1464

Hallman M, Enhorning G \& Possmayer F (1985) Composition and surface activity of normal and phosphatidylglycerol-deficient lung surfactant. Pediatr. Res. 19: 286-292

Haselier A, Akbari H, Weth A, Baumgartner W \& Frentzen M (2010) Two Closely Related Genes of Arabidopsis Encode Plastidial Cytidinediphosphate Diacylglycerol Synthases Essential for Photoautotrophic Growth. Plant Physiol. 153: 1372-1384

He Q \& Greenberg ML (2004) Post-translational regulation of phosphatidylglycerolphosphate synthase in response to inositol. Mol. Microbiol. 53: 1243-1249

Horvath SE \& Daum G (2013) Lipids of mitochondria. Prog. Lipid Res. 52: 590-614

Hsu T-H, Chen R-H, Cheng Y-H \& Wang C-W (2016) Lipid droplets are central organelles for meiosis II progression during yeast sporulation. Mol. Biol. Cell

Janitor M, Jarosch E, Schweyen RJ \& Subík J (1995) Molecular characterization of the PEL1 gene encoding a putative phosphatidylserine synthase. Yeast Chichester Engl. 11: 1223-1231

Jiang F, Rizavi HS \& Greenberg ML (1997) Cardiolipin is not essential for the growth of Saccharomyces cerevisiae on fermentable or non-fermentable carbon sources. Mol. Microbiol. 26: 481-491

Jiang F, Ryan MT, Schlame M, Zhao M, Gu Z, Klingenberg M, Pfanner N \& Greenberg ML (2000) Absence of cardiolipin in the crd1 null mutant results in decreased mitochondrial membrane potential and reduced mitochondrial function. J. Biol. Chem. 275: 22387-22394

Kandasamy P, Zarini S, Chan ED, Leslie CC, Murphy RC \& Voelker DR (2011) Pulmonary surfactant phosphatidylglycerol inhibits Mycoplasma pneumoniae-stimulated eicosanoid production from human and mouse macrophages. J. Biol. Chem. 286: 7841-7853

Kobayashi K (2016) Role of membrane glycerolipids in photosynthesis, thylakoid biogenesis and chloroplast development. J. Plant Res. 129: 565-580 
Kobayashi K, Fujii S, Sato M, Toyooka K \& Wada H (2015) Specific role of phosphatidylglycerol and functional overlaps with other thylakoid lipids in Arabidopsis chloroplast biogenesis. Plant Cell Rep. 34: 631-642

Korber M, Klein I \& Daum G (2017) Steryl ester synthesis, storage and hydrolysis: A contribution to sterol homeostasis. Biochim. Biophys. Acta BBA - Mol. Cell Biol. Lipids 1862: 1534-1545

Leber R, Landl K, Zinser E, Ahorn H, Spök A, Kohlwein SD, Turnowsky F \& Daum G (1998) Dual localization of squalene epoxidase, Erg1p, in yeast reflects a relationship between the endoplasmic reticulum and lipid particles. Mol. Biol. Cell 9: 375-386

Luévano-Martínez LA, Forni MF, Dos Santos VT, Souza-Pinto NC \& Kowaltowski AJ (2015) Cardiolipin is a key determinant for mtDNA stability and segregation during mitochondrial stress. Biochim. Biophys. Acta 1847: 587-598

Matsumura A, Higuchi J, Watanabe Y, Kato M, Aoki K, Akabane S, Endo T \& Oka T (2018) Inactivation of cardiolipin synthase triggers changes in mitochondrial morphology. FEBS Lett. 592: 209-218

Numata M, Chu HW, Dakhama A \& Voelker DR (2010) Pulmonary surfactant phosphatidylglycerol inhibits respiratory syncytial virus-induced inflammation and infection. Proc. Natl. Acad. Sci. U. S. A. 107: 320-325

Numata M, Kandasamy P, Nagashima Y, Posey J, Hartshorn K, Woodland D \& Voelker DR (2012) Phosphatidylglycerol suppresses influenza A virus infection. Am. J. Respir. Cell Mol. Biol. 46: 479487

Numata M, Nagashima Y, Moore ML, Berry KZ, Chan M, Kandasamy P, Peebles RS, Murphy RC \& Voelker DR (2013) Phosphatidylglycerol provides short-term prophylaxis against respiratory syncytial virus infection. J. Lipid Res. 54: 2133-2143

Okreglak V \& Walter P (2014) The conserved AAA-ATPase Msp1 confers organelle specificity to tailanchored proteins. Proc. Natl. Acad. Sci. U. S. A. 111: 8019-8024

Pfeiffer K, Gohil V, Stuart RA, Hunte C, Brandt U, Greenberg ML \& Schägger H (2003) Cardiolipin Stabilizes Respiratory Chain Supercomplexes. J. Biol. Chem. 278: 52873-52880

Pokorná L, Čermáková P, Horváth A, Baile MG, Claypool SM, Griač P, Malínský J \& Balážová M (2015) Specific degradation of phosphatidylglycerol is necessary for proper mitochondrial morphology and function. Biochim. Biophys. Acta

Roelants FM, Leskoske KL, Martinez Marshall MN, Locke MN \& Thorner J (2017) The TORC2-Dependent Signaling Network in the Yeast Saccharomyces cerevisiae. Biomolecules 7:

Ruggiano A, Mora G, Buxó L \& Carvalho P (2016) Spatial control of lipid droplet proteins by the ERAD ubiquitin ligase Doa10. EMBO J. 35: 1644-1655

Sandager L, Gustavsson MH, Ståhl U, Dahlqvist A, Wiberg E, Banas A, Lenman M, Ronne H \& Stymne S (2002) Storage lipid synthesis is non-essential in yeast. J. Biol. Chem. 277: 6478-6482

Schlame M \& Haldar D (1993) Cardiolipin is synthesized on the matrix side of the inner membrane in rat liver mitochondria. J. Biol. Chem. 268: 74-79

Sickmann A, Reinders J, Wagner Y, Joppich C, Zahedi R, Meyer HE, Schönfisch B, Perschil I, Chacinska A, Guiard B, Rehling P, Pfanner N \& Meisinger C (2003) The proteome of Saccharomyces cerevisiae mitochondria. Proc. Natl. Acad. Sci. U. S. A. 100: 13207-13212

Simocková M, Holic R, Tahotná D, Patton-Vogt J \& Griac P (2008) Yeast Pgc1p (YPL206c) controls the amount of phosphatidylglycerol via a phospholipase C-type degradation mechanism. J. Biol. Chem. 283: 17107-17115

Singh R, Kaushik S, Wang Y, Xiang Y, Novak I, Komatsu M, Tanaka K, Cuervo AM \& Czaja MJ (2009) Autophagy regulates lipid metabolism. Nature 458: 1131-1135

Sohlenkamp C \& Geiger O (2016) Bacterial membrane lipids: diversity in structures and pathways. FEMS Microbiol. Rev. 40: 133-159 
Sorger D, Athenstaedt K, Hrastnik C \& Daum G (2004) A yeast strain lacking lipid particles bears a defect in ergosterol formation. J. Biol. Chem. 279: 31190-31196

Spandl J, White DJ, Peychl J \& Thiele C (2009) Live cell multicolor imaging of lipid droplets with a new dye, LD540. Traffic Cph. Den. 10: 1579-1584

Stahelin RV, Digman MA, Medkova M, Ananthanarayanan B, Rafter JD, Melowic HR \& Cho W (2004) Mechanism of diacylglycerol-induced membrane targeting and activation of protein kinase Cdelta. J. Biol. Chem. 279: 29501-29512

Tuller G, Hrastnik C, Achleitner G, Schiefthaler U, Klein F \& Daum G (1998) YDL142c encodes cardiolipin synthase (Cls1p) and is non-essential for aerobic growth of Saccharomyces cerevisiae. FEBS Lett. 421: 15-18

Valachovic M, Garaiova M, Holic R \& Hapala I (2016) Squalene is lipotoxic to yeast cells defective in lipid droplet biogenesis. Biochem. Biophys. Res. Commun. 469: 1123-1128

Wang C-W (2014) Stationary phase lipophagy as a cellular mechanism to recycle sterols during quiescence. Autophagy 10: 2075-2076

Wang C-W (2015) Lipid droplet dynamics in budding yeast. Cell. Mol. Life Sci. CMLS 72: 2677-2695

Zhang M, Mileykovskaya E \& Dowhan W (2002) Gluing the Respiratory Chain Together CARDIOLIPIN IS REQUIRED FOR SUPERCOMPLEX FORMATION IN THE INNER MITOCHONDRIAL MEMBRANE. J. Biol. Chem. 277: 43553-43556

Zhong Q, Gohil VM, Ma L \& Greenberg ML (2004) Absence of cardiolipin results in temperature sensitivity, respiratory defects, and mitochondrial DNA instability independent of pet56. J. Biol. Chem. 279: 32294-32300

Zhong Q \& Greenberg ML (2003) Regulation of phosphatidylglycerophosphate synthase by inositol in Saccharomyces cerevisiae is not at the level of PGS1 mRNA abundance. J. Biol. Chem. 278: 3397833984

Zhong Q \& Greenberg ML (2005) Deficiency in mitochondrial anionic phospholipid synthesis impairs cell wall biogenesis. Biochem. Soc. Trans. 33: 1158-1161

Zhong Q, Gvozdenovic-Jeremic J, Webster P, Zhou J \& Greenberg ML (2005) Loss of function of KRE5 suppresses temperature sensitivity of mutants lacking mitochondrial anionic lipids. Mol. Biol. Cell 16: $665-675$

Zhong Q, Li G, Gvozdenovic-Jeremic J \& Greenberg ML (2007) Up-regulation of the cell integrity pathway in saccharomyces cerevisiae suppresses temperature sensitivity of the pgs1Delta mutant. J. Biol. Chem. 282: 15946-15953

Zinser E \& Daum G (1995) Isolation and biochemical characterization of organelles from the yeast, Saccharomyces cerevisiae. Yeast Chichester Engl. 11: 493-536 


\section{Figure legends}

Figure 1. Localization of GFP-Pgc1 protein is independent on induction of PG biosynthesis by exogenous inositol.

A, B Cells expressing GFP-Pgc1 protein from pCM189 plasmid (strain pgc1 $+G F P-P G C 1$, Table 1) were cultivated in SMD I+ (A) or I- (B) media without uracil. GFP fluorescence on single confocal sections (left) and composite images (GFP + DIC; right) are presented. Note that GFP-Pgc1 is localized on the surface of the labeled structures (arrows). Bar: $5 \mu \mathrm{m}$.

\section{Figure 2. GFP-Pgc1 is stably sequestered to LD.}

A-E Cells expressing GFP-Pgc1 in the presence of LD (strain $p g c 1 \Delta+G F P-P G C 1$ ).

F-H Cells expressing GFP-Pgc1 in the absence of LD (strain QMpgc1 $\Delta+G F P-P G C 1$ ).

E, H Mobility of GFP-Pgc1 was assessed using FRAP analysis. Relative fluorescence intensity changes monitored within the bleached area are plotted with error bars indicating SD $(n=20)$. Inserts depict the distribution of GFP fluorescence before (Pre-bleach), instantly after the bleaching (0) and during the recovery (times indicated in seconds after the bleaching). Bar: $5 \mu \mathrm{m}$.

Lipid droplet dye LD540 (A, red in B, D) and GFP fluorescence (C, E, F, H, green in B, D, G) on single confocal sections are presented.

Figure 3. PG of specific fatty acid composition is evenly distributed in membranes of pgc1 $\Delta$ cells.

A In each fraction of wild type, $p g c 1 \Delta$ and $\operatorname{crd} 1 \Delta$ cells, relative amount of PG (in $\%$ of total phospholipids) was evaluated. 
B PG fatty acids were estimated in mitochondrial fractions of all three analyzed strains, as well as in the ER fraction of pgcl $1 \Delta$ cells, by the gas chromatography. Relative amounts of individual fatty acids in respective fractions are shown. Mean values of at least four independent experiments \pm SEM are presented. Statistically significant differences (see Materials and Methods for details) are marked by asterisks: * $-\mathrm{p}<0.05 ; * *-\mathrm{p}<0.01$; $* * *-\mathrm{p}<0.001$.

Data information: MT, mitochondria; ER, endoplasmic reticulum; LD, lipid droplets; WT, wild type.

\section{Figure 4. Pgc1 is active whenever embedded into a lipid bilayer.}

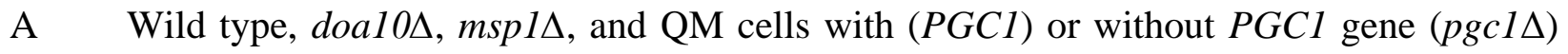
were grown in SMD I- media for $24 \mathrm{~h}$. In vitro phospholipase activity of Pgc1 in isolated subcellular fractions (HO, cell homogenate; ER, endoplasmic reticulum; MT, mitochondria; LD, lipid droplets) was measured in terms of relative amounts of NBDDAG, a product of Pgc1-mediated hydrolysis of NBD-PG. Mean values of at least three and two independent experiments \pm SEM are presented for $P G C l$ and pgcl $\triangle$ strains, respectively.

B LD with increasing amounts of Pgc1 protein were isolated from strains $\operatorname{pgcl\Delta }$, WT, and $\mathrm{WT}+$ PGC1. In vitro activity of Pgc1 in mixtures of these $\mathrm{LD}$ with the $\mathrm{ER}$ or mitochondrial (MT) fraction isolated from $p g c 1 \Delta$ strain was analyzed.

$\mathrm{C}$ In vitro activities of $\mathrm{Pgc1}$ in mixtures of $\mathrm{LD}$ isolated from the strain overexpressing $P G C 1$ (WT + PGC1) with membrane bilayers of different origin were analyzed. Mixtures containing complete ER and mitochondrial (MT) membrane fractions (black), membranes composed of isolated lipids from these fractions (white), and membranes composed of synthetic phospholipids (PC/PE; grey) are compared.

Data information: In (B, C), mean values of at least four independent experiments \pm SEM are presented. In A-C, Statistically significant (see Materials and Methods for details) differences are marked by asterisks: * - p $<0.05 ; * *-\mathrm{p}<0.01 ; * * *-\mathrm{p}<0.001$. 


\section{Figure 5. C-terminal truncation disrupts Pgc1 function.}

A Levels of $P G C 1, P G C 1^{1-274}$, and $P G C 1^{1-297}$ mRNA in strains expressing the respective Pgc1 protein versions either with or without GFP tagging on pgcls background were compared. WT + EV strain was used as a control. The results were normalized to ACT1 and IPPI mRNA levels; the wild type PGCl mRNA level was set to 1 . Mean values of at least two independent experiments \pm SEM are presented.

B Using anti-GFP antibody, GFP-tagged Pgc1 versions were tracked on immunoblot. Por1 was used as a loading control (bottom panel). Protein levels in strains with (pgcl $\Delta$ derived; dashed line) and without LD (QMpgc1 $\Delta$-derived; dotted line) were compared.

C GFP-Pgc1 $1^{1-274}$ (strain $p g c 1 \Delta+G F P-P G C 1^{1-274}$ ) was localized by fluorescence microscopy. A single confocal section is presented. Bar: $5 \mu \mathrm{m}$.

D In vitro activities of Pgc1, $\mathrm{Pgcl}^{1-274}$ and $\mathrm{Pgcl}^{1-297}$ in cell homogenates (strains pgc1 $1+P G C 1, p g c 1 \Delta+P G C 1^{1-274}$ and $p g c 1 \Delta+P G C 1^{1-297}$ ) were measured in terms of relative amounts of NBD-DAG, a product of Pgc1-mediated hydrolysis of NBD-PG. Mean values of at least three independent experiments \pm SEM are presented.

E Using thin layer chromatography, phospholipid profiles of strains overexpressing different Pgc1 versions were measured. Lipids extracted from cell homogenates were separated and visualized as described in Materials and Methods. PC, phosphatidylcholine; PI, phosphatidylinositol; PS, phosphatidylserine; PE, phosphatidylethanolamine; PG, phosphatidylglycerol; PA, phosphatidic acid; CL, cardiolipin; EV, empty vector.

\section{Figure 6. Model of PG homeostasis in S. cerevisiae.}

Yeast PG is synthesized at the inner mitochondrial (MT) membrane (dark grey) and freely spreads from there all over the cellular membrane system. In other membranes, its levels are kept low by the action of Pgc1. Inactive form of Pgc1 is stored at the surface of 
LD. Through the continuous contacts of LD with the ER membrane, Pgc1 diffuses to the ER and gets activated. Further spreading of the enzyme to other membranes is highly likely. Our data indicated Pgc1 activity in the outer mitochondrial membrane, for example. At membranes, Pgc1 becomes accessible for rapid ubiquitylation by local factors, such as Doa10 in the ER, and possibly Msp1 at the outer mitochondrial membrane. Actual PG levels are then a result of balanced i) PG synthesis, ii) Pgc1mediated PG degradation triggered by the release of the ezyme from LD, and iii) Pgc1 turnover.

\section{Figure EV1. Expression of GFP-Pgc1 protein complements phenotype of $p g c 1 \Delta$ mutant.}

Phospholipids isolated from the yeast strains (WT+EV, pgcl $1+\mathrm{EV}, p g c 1 \Delta+P G C 1$, $\operatorname{pgc} 1 \Delta+G F P-P G C 1)$ grown on SMD I- media without uracil were separated on thin layer chromatography and visualized as described in Materials and Methods. Note the absence of PG accumulation in the strains transformed with vector expressing PGCl or GFPPGCl gene. PC, phosphatidylcholine; PI, phosphatidylinositol; PS, phosphatidylserine; PE, phosphatidylethanolamine; PG, phosphatidylglycerol; PA, phosphatidic acid; CL, cardiolipin; EV, empty vector.

\section{Figure EV2. LD are dispensable for PG degradation.}

Wild type and QM cells were cultivated in SMD I- media for $24 \mathrm{~h}$. Phospholipids were extracted from cell homogenate (HO) and isolated mitochondrial fraction (MT), separated by thin layer chromatography and visualised by iodine vapor. PG levels were quantified as described in Materials and Methods. Mean values of at least five independent experiments \pm SEM are presented.

Figure EV3. Fluorescently labelled PG is incorporated both to lipid mono- and bilayers. 
Incorporation of NBD-PG into the lipid monolayer at the surface of LD (empty bars) and mitochondrial membranes (full bars) was tested. In both cases, $0.8 \mu \mathrm{g}$ NBD-PG was solved in $0.1 \%$ Triton-X100 and added to suspension containing distinct amount of isolated wild type cellular fraction $(20 \mu \mathrm{g}$ of LD proteins, $175 \mu \mathrm{g}$ of mitochondrial proteins) in $10 \mathrm{mM}$ Tris/HCl, $\mathrm{pH}$ 7.4. Final volume of the mixture was $240 \mu 1$. Mixtures were incubated at $30{ }^{\circ} \mathrm{C}$ on shaker for 15 or 30 minutes. Organelles were either floated (LD) or pelleted (mitochondria) by centrifugation and washed. Extracted phospholipids were laid on thin layer chromatography plate and fluorescent NBD-PG was visualized by TLC scanner (Camag). Mean values of two independent experiments \pm SEM are presented.

\section{Figure EV4. Presence of intact membranes enhances phospholipase activity of Pgc1.}

In vitro activities of $\mathrm{Pgc1}$ in the wild type and QM strains were measured in cell homogenates prepared either by Dounce homogenizer as described in Materials and Methods (empty bars) or by glass beads (full bars). Glass bead homogenization was performed as follows: washed cells were suspended in $1 \mathrm{ml}$ of $10 \mathrm{mM}$ Tris/ $\mathrm{HCl}, \mathrm{pH} 7.4$ and disrupted with glass beads (diameter $0.4 \mathrm{~mm}$ ) in FastPrep (MP Biomedicals), for $2 \times$ $45 \mathrm{~s}$ at the highest speed with $5 \mathrm{~min}$ cooling on ice between the runs. Mean values of at least four independent experiments \pm SEM are presented. Statistically significant (see Materials and Methods for details) differences are marked by asterisks: $* * *-p<0.001$. 
bioRxiv preprint doi: https://doi.org/10.1101/308874; this version posted April 26, 2018. The copyright holder for this preprint (which was not certified by peer review) is the author/funder, who has granted bioRxiv a license to display the preprint in perpetuity. It is made available under

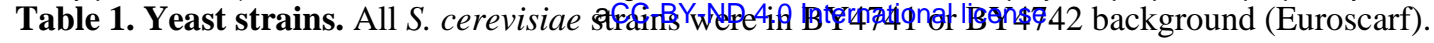

\begin{tabular}{|c|c|c|}
\hline Strain & Genotyp & Source \\
\hline pgcls & MAT $\alpha$ his3, leu2, ura3, lys2, pgc1::KanMX4 & Euroscarf \\
\hline pgcl $\Delta+\mathrm{EV}$ & MAT $\alpha$ his3, leu2, ura3, lys2, pgc1::KanMX4, pCM189 (URA3) & This study \\
\hline$p g c 1 \Delta+P G C l$ & MATa his3, leu2, ura3, lys2, pgc1::KanMX4, pCM189-PGC1 & This study \\
\hline pgcl $1 \Delta+G F P-P G C 1$ & MAT $\alpha$ his3, leu2, ura3, lys2, pgc1::KanMX4, pCM189-GFP-PGC1 & This study \\
\hline $\operatorname{pgcl\Delta }+P G C 1^{1-274}$ & MAT $\alpha$ his3, leu2, ura3, lys2, pgc1::KanMX4, pCM189-PGC1 $1^{1-274}$ & This study \\
\hline 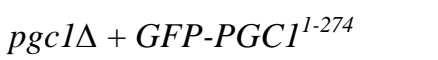 & MAT $\alpha$ his3, leu2, ura3, lys2, pgc1::KanMX4, pCM189-PGC1 $1^{1-274}$ & This study \\
\hline pgcl $1 \Delta+P G C 1^{1-297}$ & MATa his3, leu2, ura3, lys2, pgc1::KanMX4, pCM189-PGC1 $1^{1-297}$ & This study \\
\hline pgcl $1+G F P-P G C 1^{1-297}$ & MAT $\alpha$ his3, leu2, ura3, lys2, pgc1::KanMX4, pCM189-PGC1 $1^{1-297}$ & This study \\
\hline Wild type (WT) & MATa his3, leu2, met15, ura3, lys 2 & Euroscarf \\
\hline $\mathrm{WT}+\mathrm{EV}$ & MATa his3, leu2, met15, ura3, lys2, pCM189 (URA3) & This study \\
\hline $\mathrm{WT}+P G C 1$ & MATa his3, leu2, met15, ura3, lys2, pCM189-PGC1 & This study \\
\hline $\operatorname{crdl\Delta }$ & MATa his3, leu2, met15, ura3, crd1::KanMX4 & Euroscarf \\
\hline doal0s & MATa his3, leu2, met15, ura3, doal0::KanMX4 & Euroscarf \\
\hline $\operatorname{pgc} 1 \Delta d o a 10 \Delta$ & MATa his3, leu2, ura3, lys2, pgc1::HIS3, doa10::KanMX4 & This study \\
\hline$m s p 1 \Delta$ & MATa his3, leu2, met15, ura3, msp1::KanMX4 & Euroscarf \\
\hline $\operatorname{pgcl\Delta mspl\Delta }$ & MAT $\alpha$ his3, leu2, ura3, lys2, pgc1::HIS3, msp1::KanMX4 & This study \\
\hline QM & $\begin{array}{l}\text { MATa his3, leu2, met } 15 \text {, ura3, dgal::KanMX4, lro1::KanMX4, } \\
\text { are1::KanMX4, are } 2:: \text { KanMX4 }\end{array}$ & (Athenstaedt, 2011) \\
\hline QMpgc1 $1 \Delta$ & $\begin{array}{l}\text { MATa his3, leu2, met15, ura3, dgal::KanMX4, lrol::KanMX4, } \\
\text { are1::KanMX4, are } 2: \text { KanMX4, pgc1::HIS3 }\end{array}$ & This study \\
\hline $\mathrm{QM} p g c 1 \Delta+G F P-P G C 1$ & $\mathrm{QM} p g c 1 \Delta, \mathrm{pCM} 189-G F P-P G C 1$ & This study \\
\hline $\mathrm{QM} p g c 1 \Delta+G F P-P G C 1^{1-274}$ & $\mathrm{QM} p g c 1 \Delta, \mathrm{pCM} 189-G F P-P G C 1^{1-274}$ & This study \\
\hline $\mathrm{QM} p g c 1 \Delta+G F P-P G C 1^{1-297}$ & $\mathrm{QM} p g c 1 \Delta, \mathrm{pCM} 189-G F P-P G C 1^{1-297}$ & This study \\
\hline
\end{tabular}


A

d. April 26, 2018. The copyright holder for this preprint (which was not
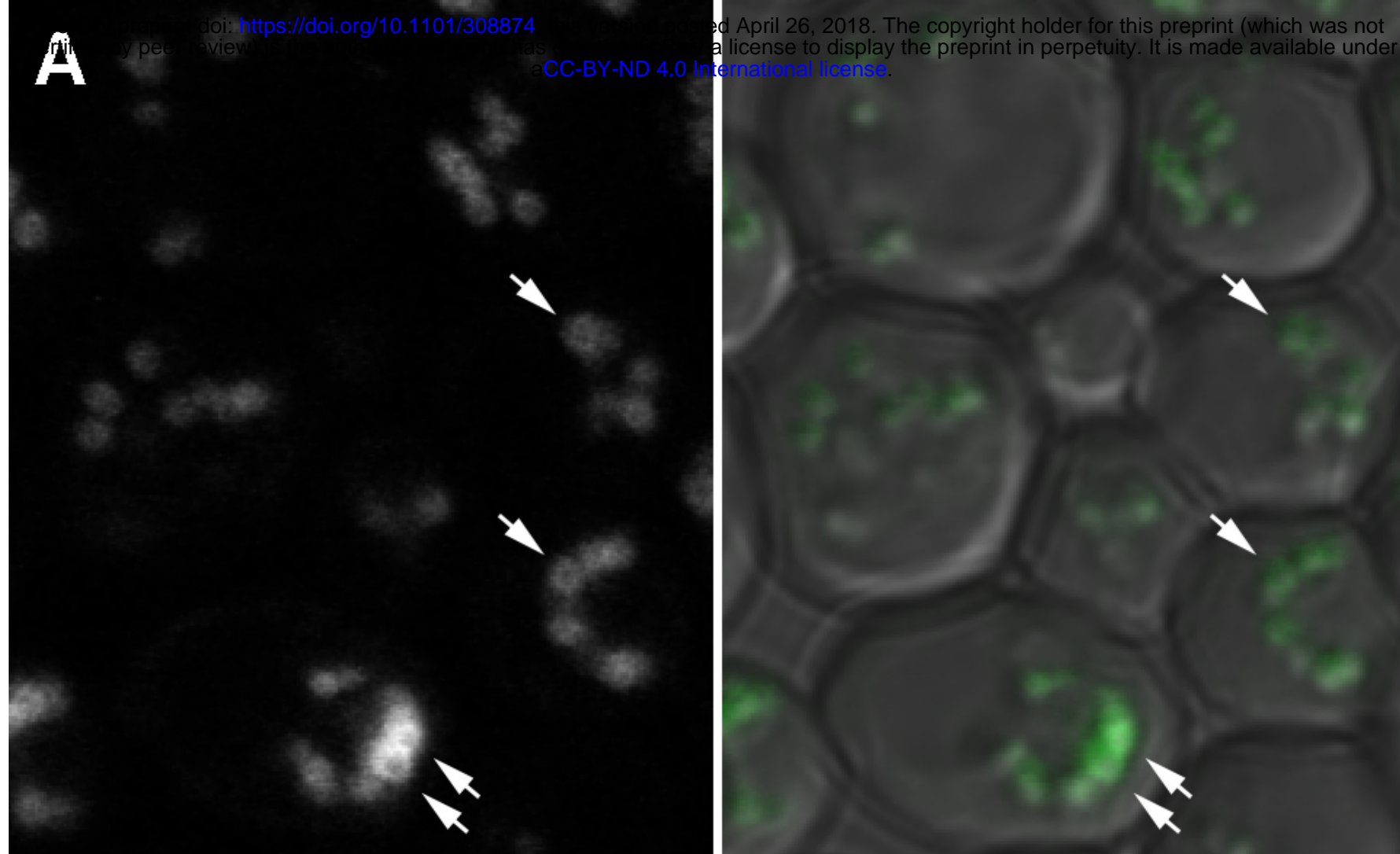

ㅇ.

$\mathrm{k}$

$\mathrm{k}$

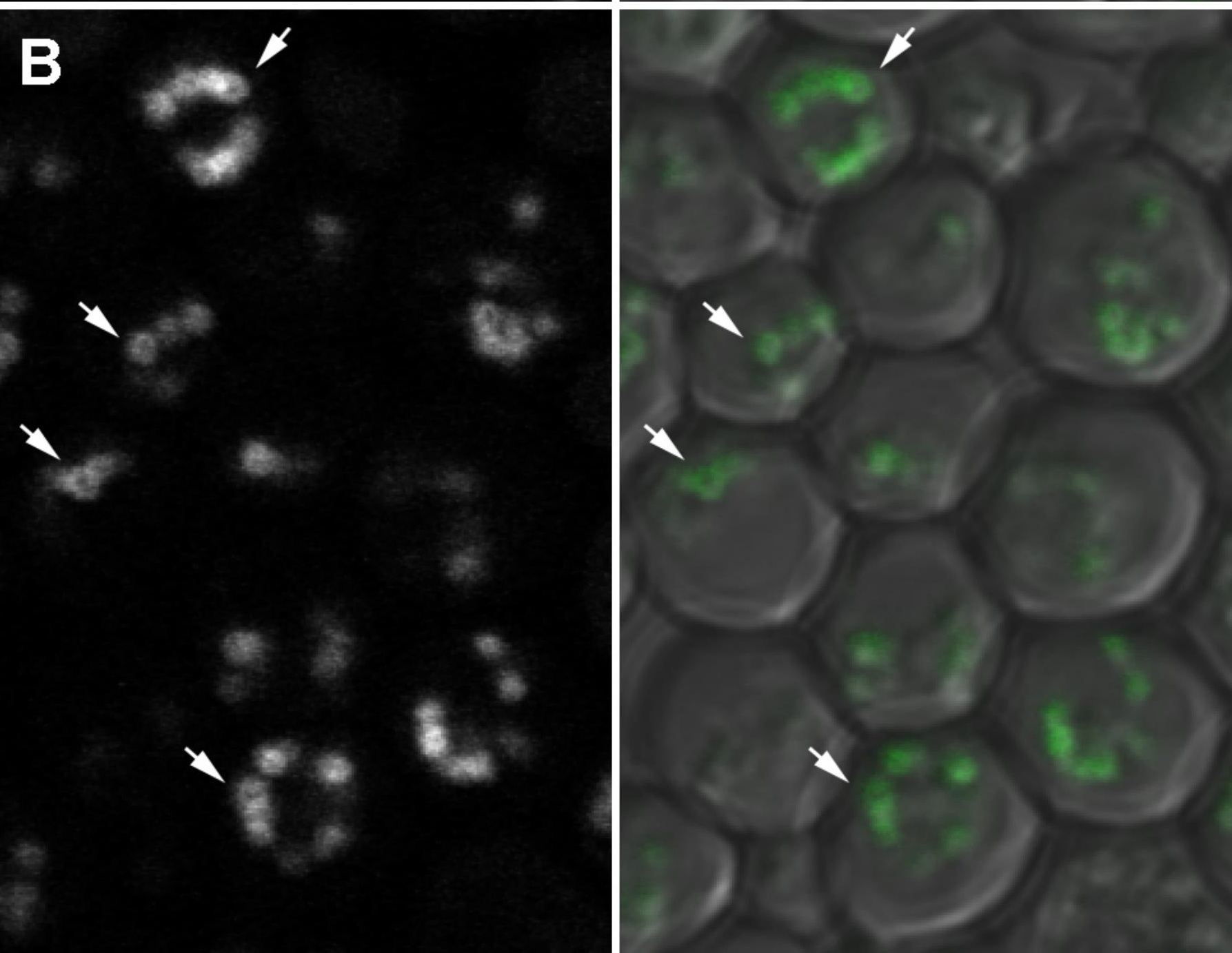



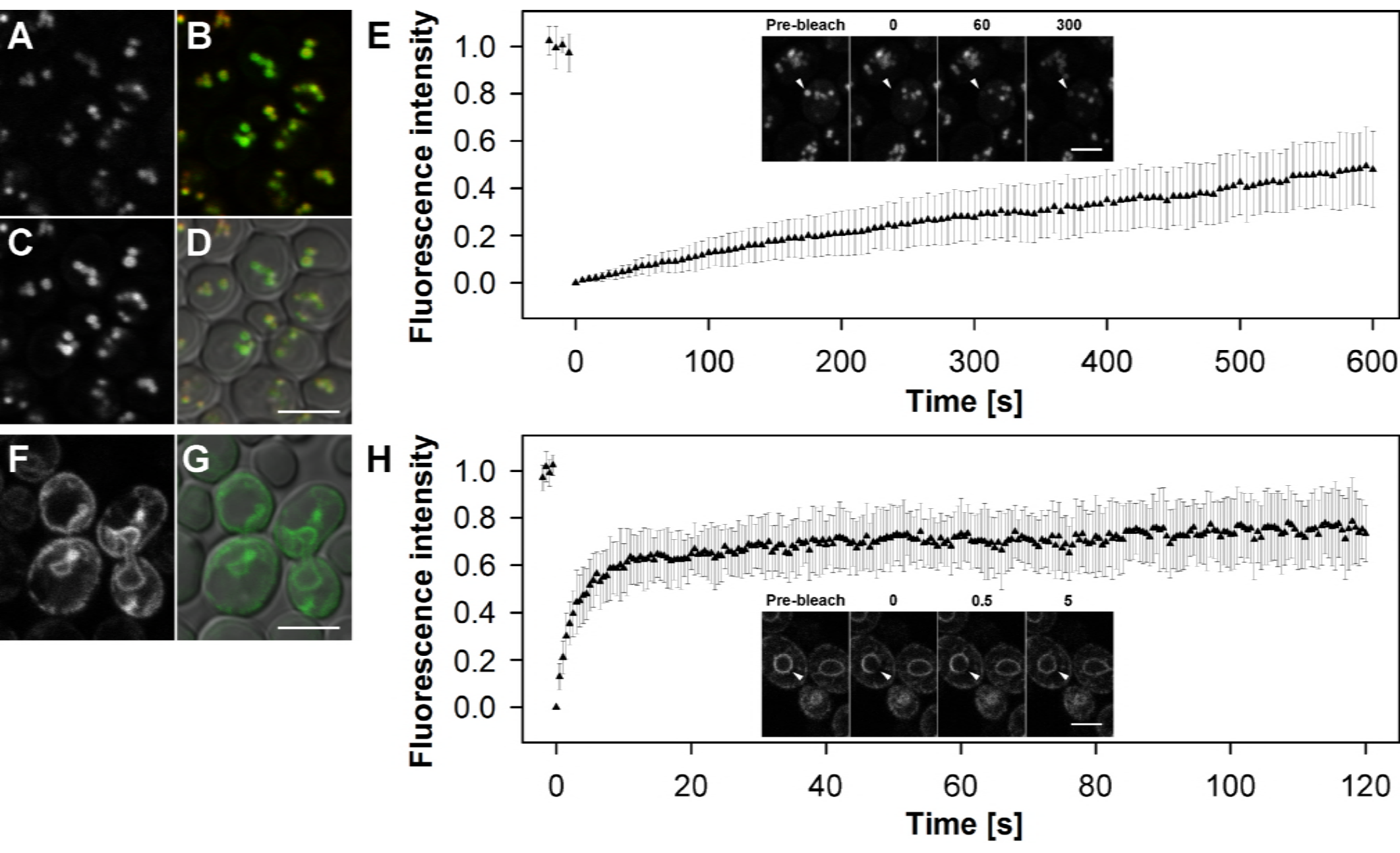
bioRxiv preprint doi: $h$ tps://doi.org/10.1101/308874; this version posted April 26, 2018. The copłight holder for this preprint (which was-not certified by peer review is der $\quad$ de $h$ granted bioRxiv a license to display the preprint in perpetuity. It is made available $\boldsymbol{\iota}$ der
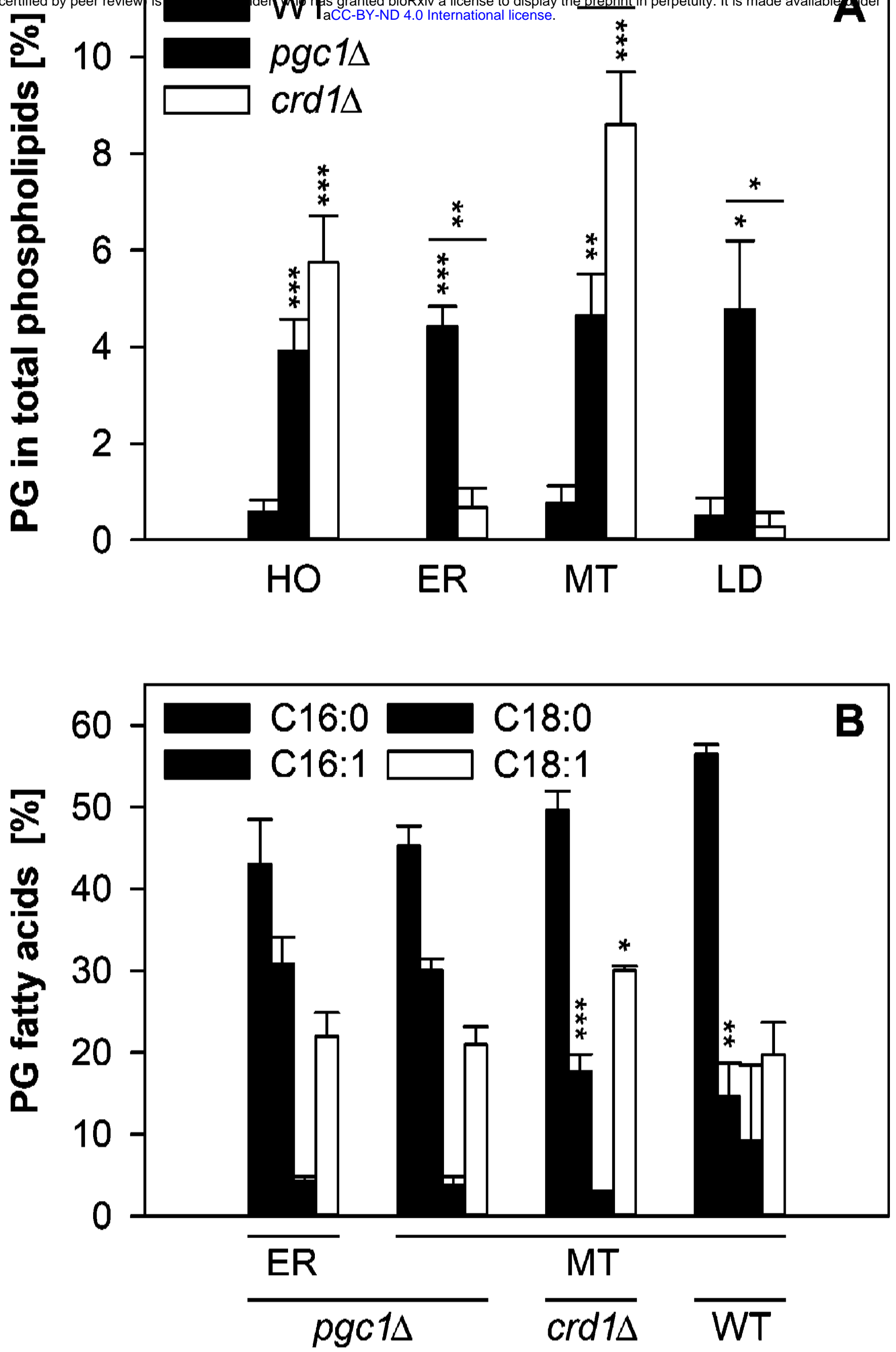

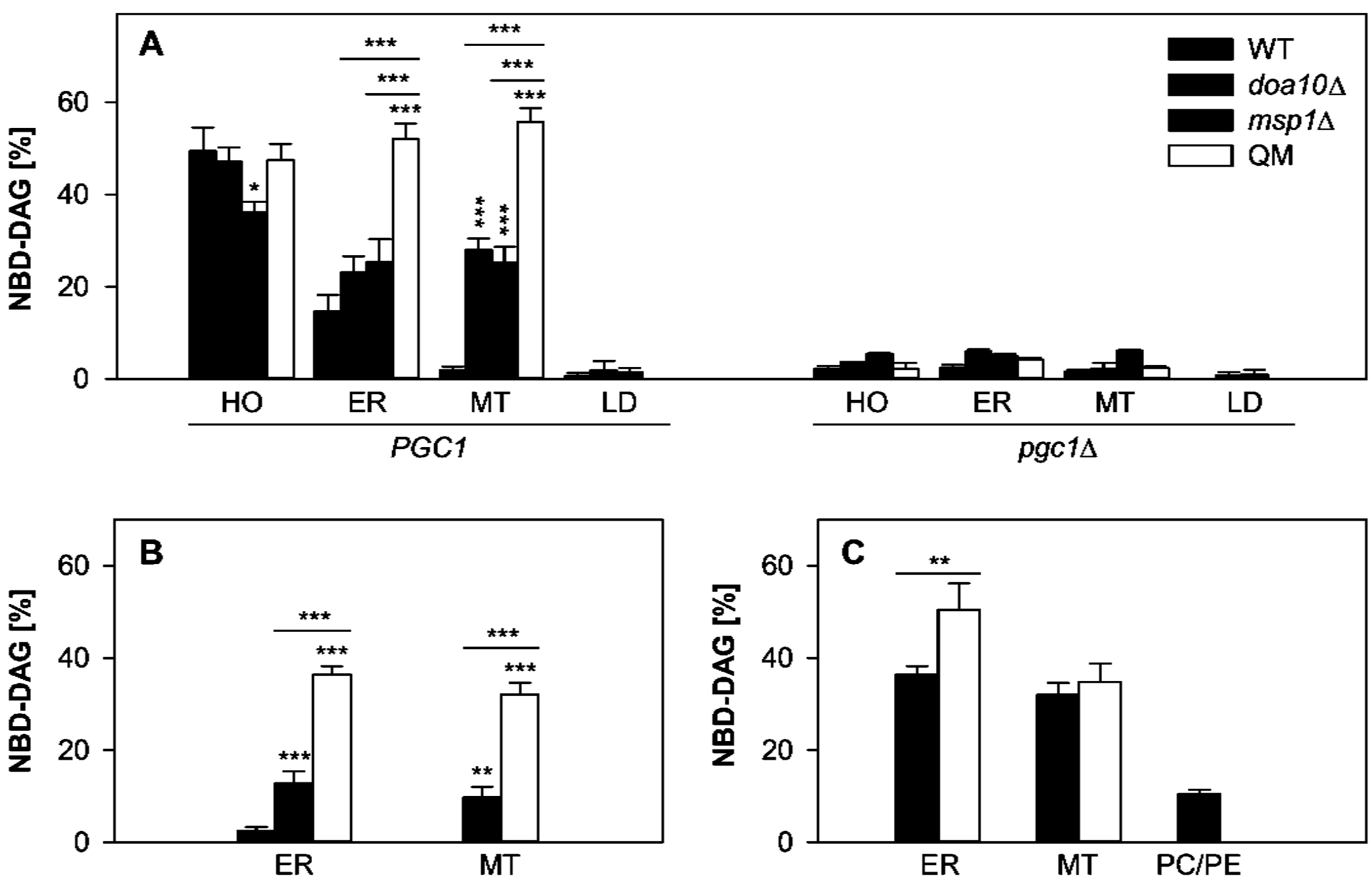


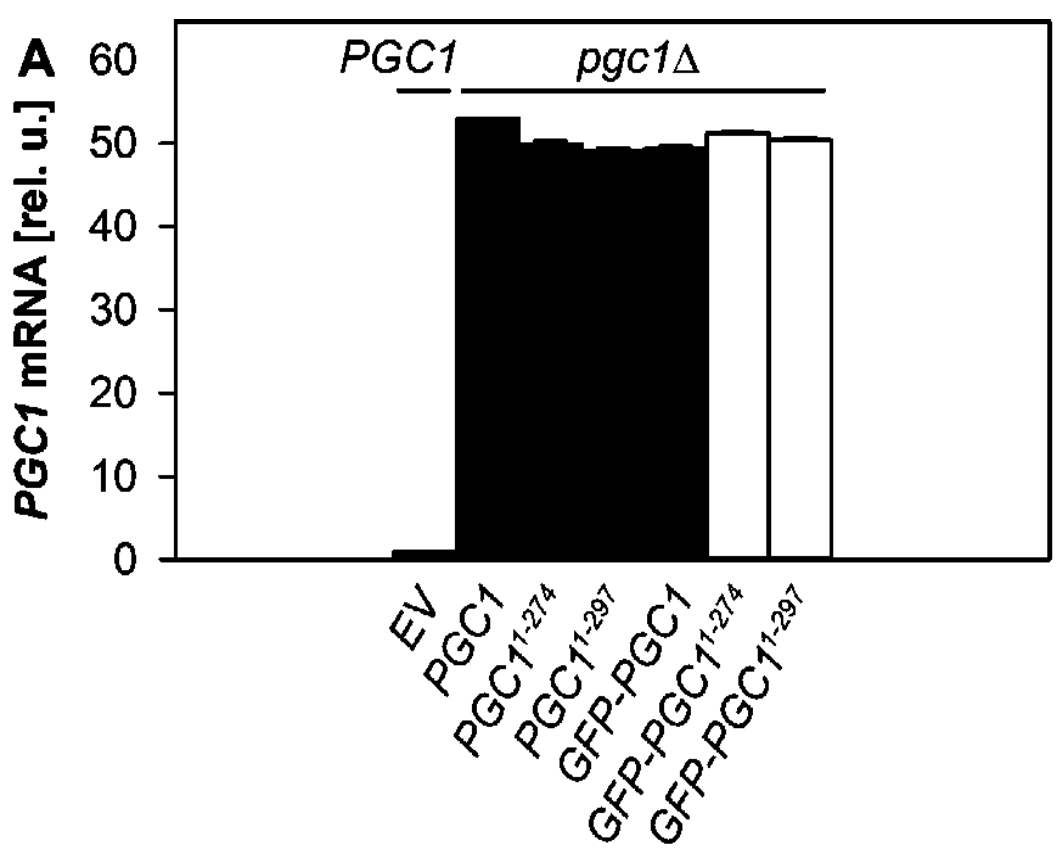

B

$$
\text { GFP-PGC1 } \quad \text { GFP-PGC1 } \text { 1-297 }^{1-29}
$$

$\mathrm{kDa}$ $70-$

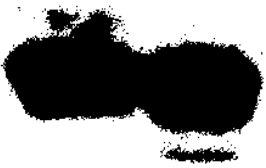

$25-$
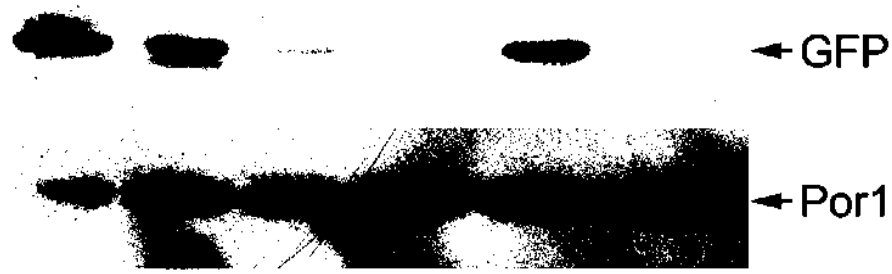
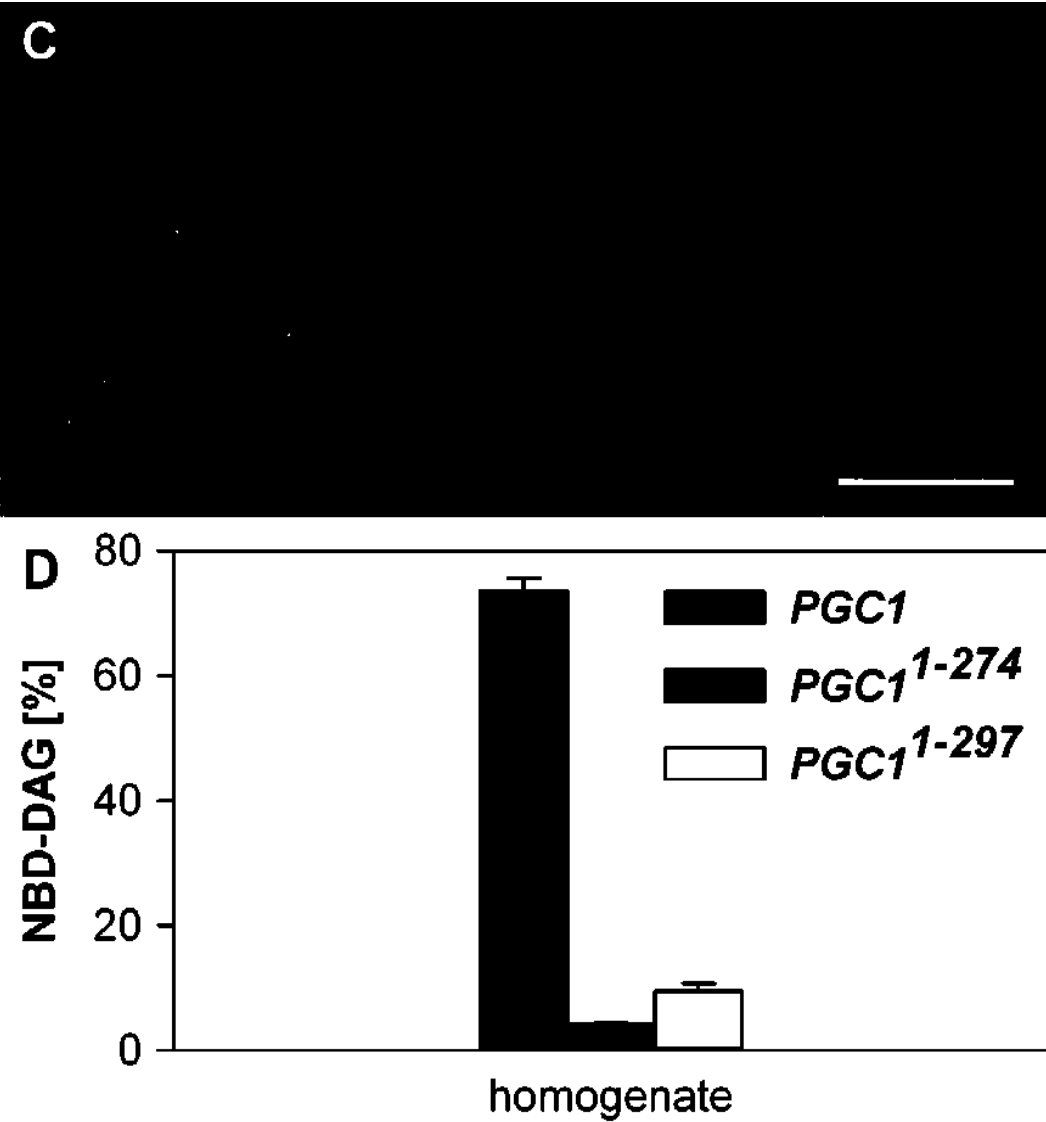

GFP-Pgc1
GFP-Pgc1 $1^{1-274}$

E $P G C 1$

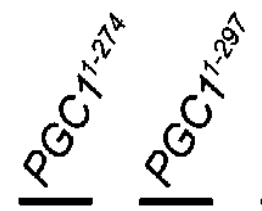<smiles>COC(C)=O</smiles>
pgc1s

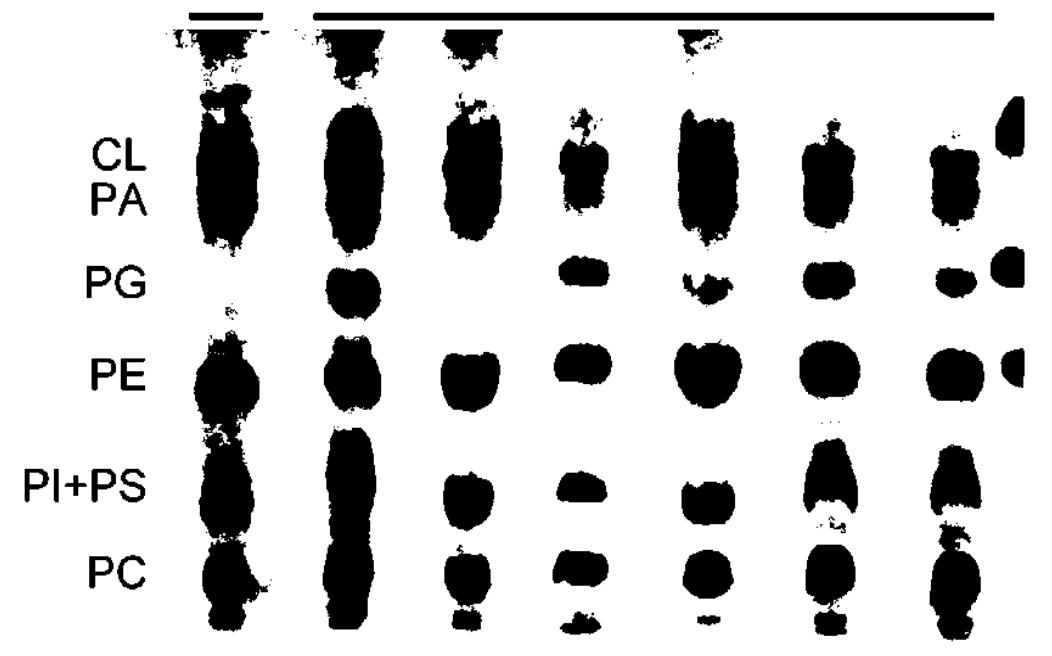


bioRxiv preprint doi: https://doi.org/10.1101/308874; this version posted April 26, 2018. The copyright holder for this preprint (which was not certified by peer review) is the author/funder, who has granted bioRxiv a license to display the preprint in perpetuity. It is made available under aCC-BY-ND 4.0 International license.
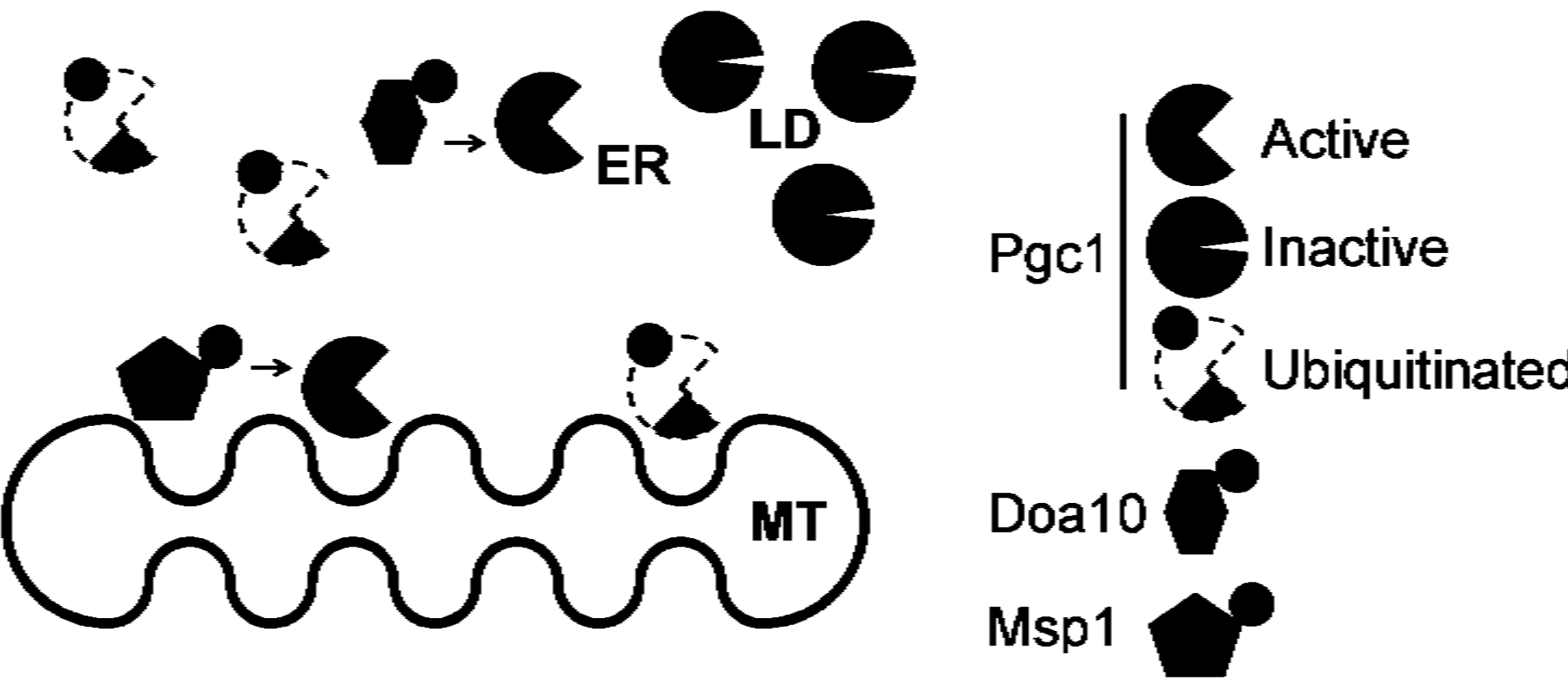
bioRxiv preprint doi: https://doi.org/10.1101/308874; this version posted April 26, 2018. The copyright holder for this preprint (wh was not certified by peer review) is the author/funder, who has granted bioRxiv a license to display the preprint in perpetuity. It is made (vailable under aCC-BY-ND 4.0 International license.
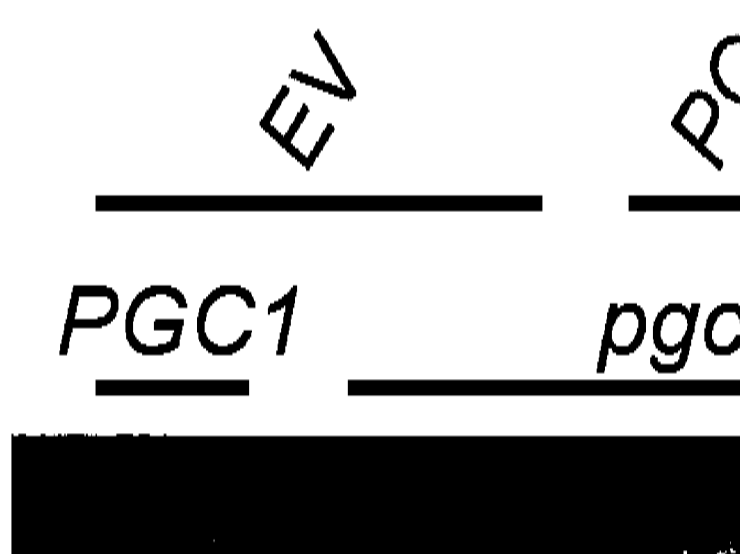
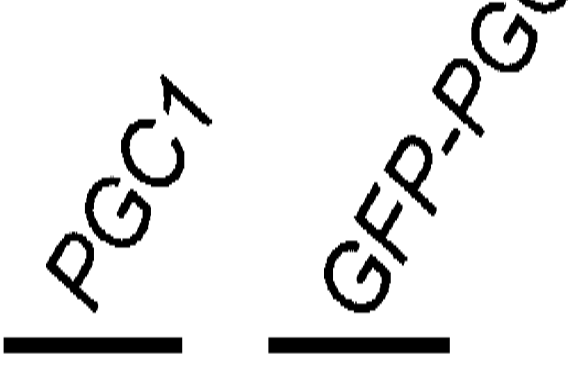

\section{$\mathrm{CL}$ \\ PA}

PG

PE

PI+PS
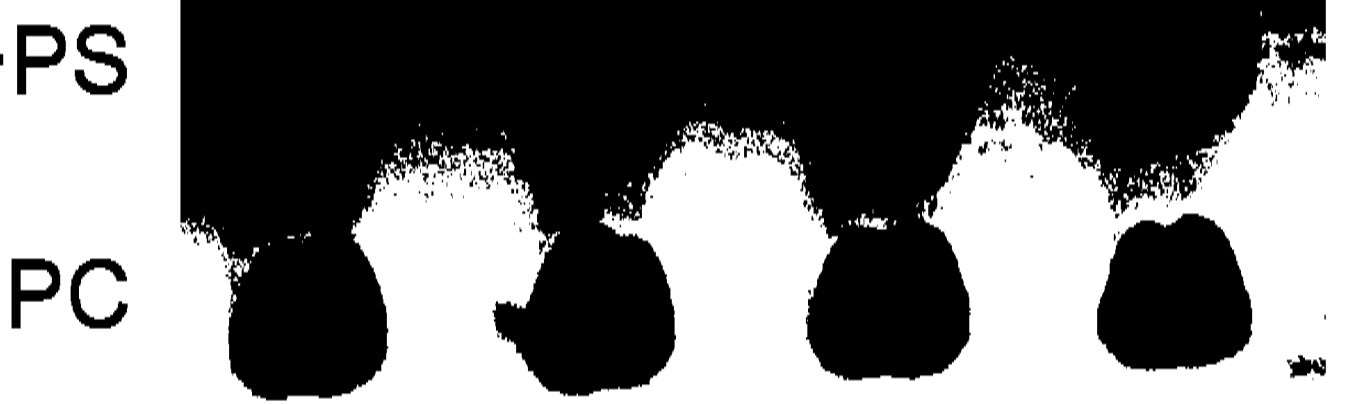


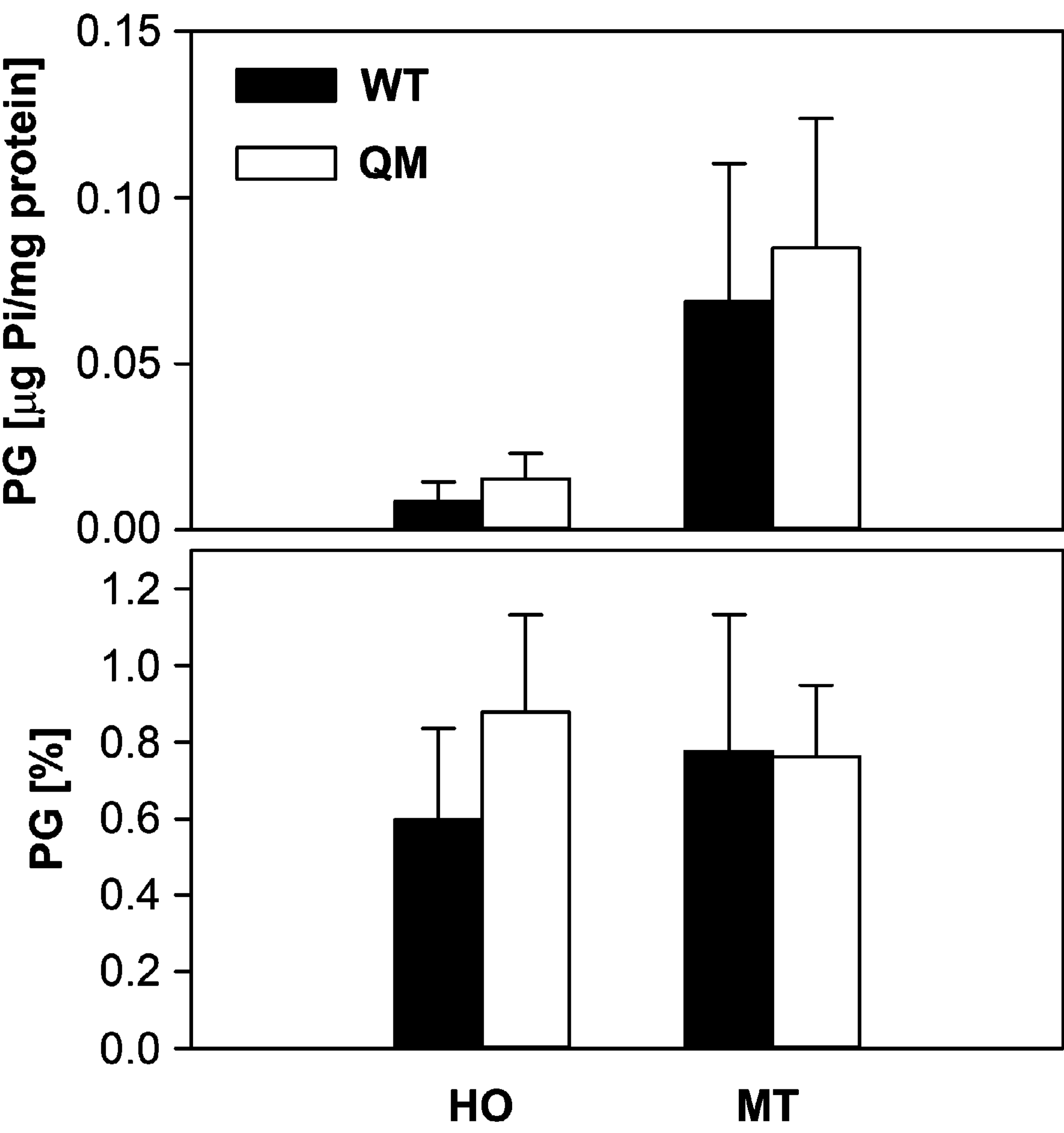


bioRxiv preprint doi: https://doi.org/10.1101/308874; this version posted April 26, 2018. The copyright holder for this preprint (which was not certified by peer review) is the author/funder, who has granted bioRxiv a license to display the preprint in perpetuity. It is made available under aCC-BY-ND 4.0 International license.

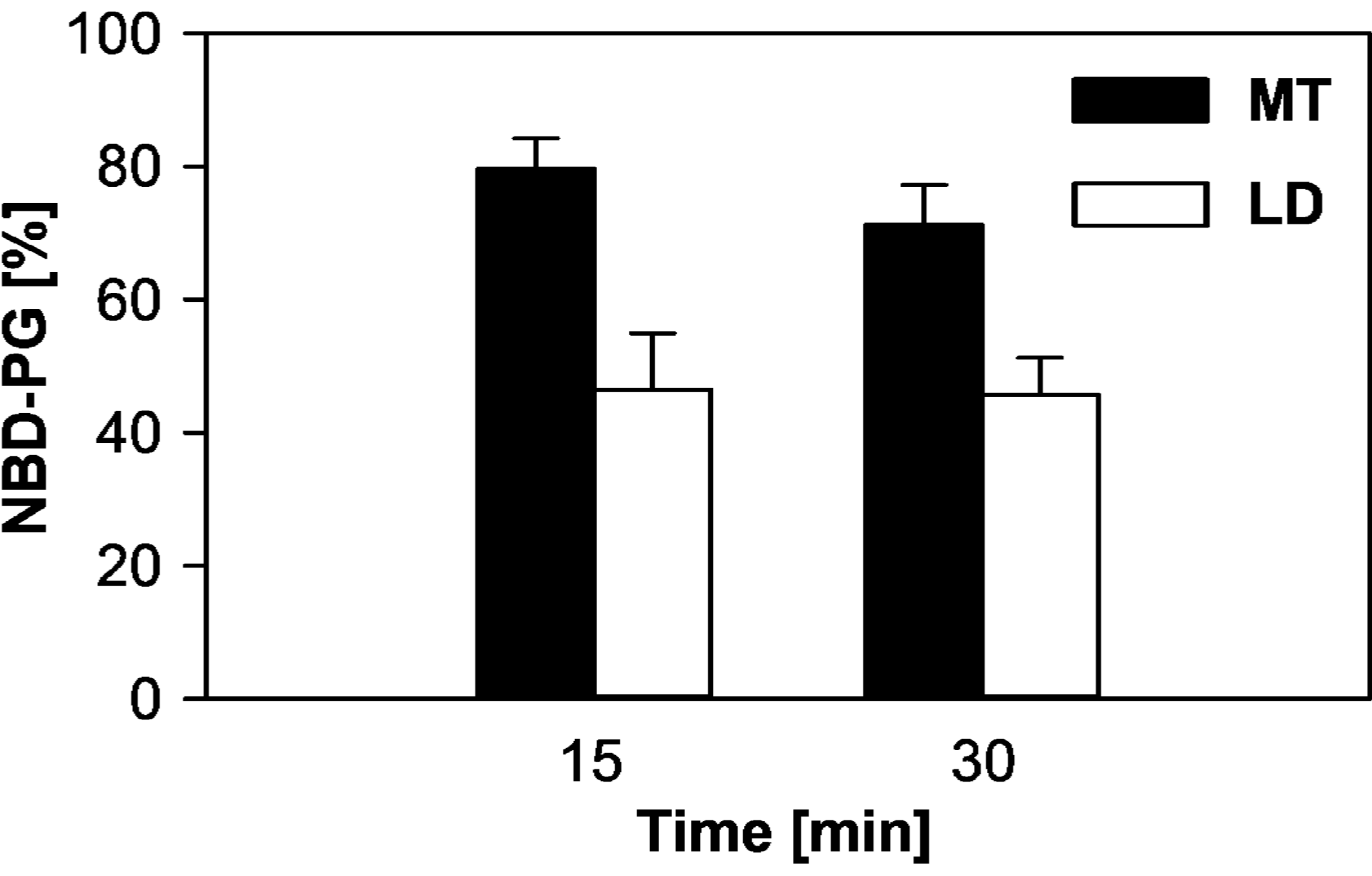


